Research Article

\title{
Response of RPC-Filled Circular Steel Tube Columns under Monotonic and Cyclic Axial Loading
}

\author{
Qin Rong $\mathbb{D}^{1,2}$ Yusheng Zeng, ${ }^{2}$ Lanhui Guo, ${ }^{2}$ Xiaomeng Hou $\mathbb{D}^{2},{ }^{2}$ and Wenzhong Zheng ${ }^{2}$ \\ ${ }^{1}$ School of Architecture and Civil Engineering, Harbin University of Science and Technology, Harbin 150080, China \\ ${ }^{2}$ Key Lab of Structures Dynamic Behavior and Control of the Ministry of Education, Harbin Institute of Technology, \\ Harbin 150090, China \\ Correspondence should be addressed to Qin Rong; hitrongqin@126.com and Xiaomeng Hou; houxiaomeng@gmail.com
}

Received 4 February 2019; Accepted 13 March 2019; Published 15 April 2019

Academic Editor: Yuri S. Karinski

Copyright (C) 2019 Qin Rong et al. This is an open access article distributed under the Creative Commons Attribution License, which permits unrestricted use, distribution, and reproduction in any medium, provided the original work is properly cited.

Results from mechanical tests on thirteen reactive powder concrete- (RPC-) filled circular steel tube (RFCT) columns under monotonic and cyclic axial loading are presented in this paper. The test variables include monotonic and cyclic loadings, confinement coefficient, and diameter of the steel tube. The test results show that the envelope curves of specimens under cyclic loading were similar to the load-deformation curves of the specimens under monotonic loading. Confinement coefficient had a significant influence on the failure modes of RFCT columns. With an increase in confinement coefficient of 0.53 to 0.98 , the failure mode transformed from shear failure to compressive failure for specimens under monotonic and cyclic loading. In the elastic stage, no confining effect was provided by the steel tube to the RPC since Poisson's ratio of steel was larger than the transverse deformation coefficient of RPC. Beyond the elastic stage, the axial compressive strength and ultimate strain of RPC increased significantly due to the confining effect when compared to unconfined RPC. Stress of the steel tube and RPC was investigated by using an elastic-plastic analytical model. Before yielding of the steel tube, stress development in the tube was faster in the longitudinal direction than in the hoop direction. The results of the experiment indicate that the compressive strength of RPC could be predicted by Mander's model for confined concrete. Based on Mander's model, an equation is extended to calculate the axial compressive strength of RFCT columns, and the predicted results are in good agreement with the test results. Based on comparative analysis of 180 RFCT columns axial compressive tests, the equation given by EC4 considering the confinement effect can be applied to predict the compressive strength of RFCT columns.

\section{Introduction}

Research interests on reactive powder concrete (RPC) has been growing in civil engineering due to its ultrahigh strength, excellent durability, and high toughness [1]. For instance, compressive strength of RPC is $100-800 \mathrm{MPa}$ and elasticity modulus is $40 \mathrm{GPa}-60 \mathrm{GPa}$ [2-4]. Application of RPC has increased recently $[5,6]$. However, the main disadvantages of RPC are mainly the lower ratio of ultimate strain to peak strain, which make it more brittle than normal strength concrete (NSC) or high-strength concrete (HSC). Further, due to more compactness, it is more susceptible to fire-induced spalling [7-10]. Recently, an experimental research on fire resistance was performed on seven reinforced RPC columns by our research group. As shown in Figure 1, spalling occurred in all columns with $2 \%$ steel fibers. This indicates that the spalling of RPC is a huge challenge, and ways should be explored on making RPC structures safe against fire [9].

Pouring RPC into steel tube is capable of reducing the fire-induced spalling of RPC. Further, RPC-filled circular steel tube (RFCT) columns are expected to possess improved ductility and axial compressive capacity. Moreover, the seismic behavior of RFCT columns is improved when compared to the conventionally reinforced RPC or NSC columns. This is mainly because the confining effect provided by the steel tube enhances the strength and ultimate strain of RPC. Therefore, application of RFCT columns is expected to be promising and better structural performance can be achieved [11]. Currently, RPC-filled high-strength 


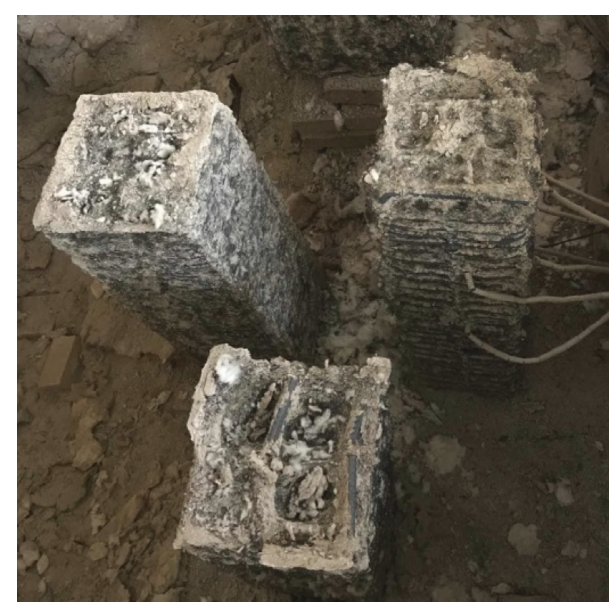

FIGURE 1: Spalling of RPC columns in fire.

steel columns were applied in the construction of Techno Station in Tokyo, Japan. As compared with normal strength materials, the dimension of the column was reduced from $800 \mathrm{~mm}$ to $500 \mathrm{~mm}$ [12].

Understanding the behavior of columns under axial loading is the basic for the structural design $[13,14]$. Researchers have investigated HSC-filled steel tube columns and RFCT columns. Liu et al. [15] investigated the axial compressive behavior of eighteen circular tube columns filled with HSC for which the compressive strength of concrete varied from 60 to $94 \mathrm{MPa}$. The external diameter of the columns ranged from $133 \mathrm{~mm}$ to $140 \mathrm{~mm}$. Axial compressive strength of HSC-filled tube column was higher than that of normal concrete-filled tube column having the same size because the HSC core could carry larger external load when compared to normal concrete core. Qi et al. [16] investigated the behavior of circular tube columns filled with HSC having compressive strength of $76.9 \mathrm{MPa}$ when subjected to axial loading. The external diameter and the thickness of the tube were, respectively, $210 \mathrm{~mm}$ and $3 \mathrm{~mm}$. Test results showed that HSC-filled specimens exhibited greater axial load capacity when compared to normal concrete filled tube columns having same volumetric steel ratio. Confinement coefficient had a large influence on the failure mode of HSCfilled columns.

Lin et al. [17] investigated the behavior of short RFCT columns subjected to axial compression. The diameter and length of columns were $133 \mathrm{~mm}$ and $400 \mathrm{~mm}$, respectively. Compressive strength of RPC infill varied from $109 \mathrm{MPa}$ to $154 \mathrm{MPa}$, and thickness of steel tube varied from $3 \mathrm{~mm}$ to $12 \mathrm{~mm}$. Experimental results showed that RFCT columns with higher confinement coefficient (confinement coefficient $\left.\xi=A_{\mathrm{s}} f_{\mathrm{y}} /\left(A_{\mathrm{c}} f_{\mathrm{c}}\right)\right)$ were more effective to prevent shear failure. Liu et al. [18] investigated RFCT columns subjected to axial compression. It was reported that RFCT columns exhibited lower confinement effect when compared to steel tubes filled with normal concrete. A total of 56 circular and square RFCT short columns under axial load with high steel strength up to $780 \mathrm{MPa}$ and RPC with compressive strength up to $190 \mathrm{MPa}$ were conducted by Xiong et al. [19]. Further, the flexural behavior, moment-axial force interaction, and overall buckling resistances of RFCT columns subjected concentric and eccentric compression were investigated $[20,21]$. Results showed that as compared with concentrically loaded columns, the eccentrically loaded columns had better ductility.

While some research has been conducted on the behavior of RFCT columns, no systematic experimental research exists on the behavior of RFCT columns subjected to cyclic axial compressive load. The cyclic loading test can be utilized to measure the unloading and reloading branches of columns $[22,23]$. The response of RFCT columns can be quantified by the unloading and reloading stiffness process. In addition, the influence of confinement coefficient on the failure modes of RFCT columns is still unknown. The differences between RPCfilled steel tubes and NSC/HSC infilled steel tubes are that the compressive strength of RPC is higher than NSC/HSC, but the lateral deformation of RPC is lower than NSC/ HSC. Further, the failure mode of RPC-filled steel tubes is different with NSC/HSC at same confinement coefficient. Therefore, it is essential to experimentally investigate the behavior of RFCT stub columns subjected to cyclic axial loading.

To overcome the abovementioned limitations and to extend the understanding on the behavior of RFCT under cyclic loading, this paper experimentally investigates short RFCT columns under monotonic and cyclic axial load with a relatively lager cross section, with the diameter of specimens ranging between $219 \mathrm{~mm}$ and $273 \mathrm{~mm}$. A case analysis is done to reveal the effect of different factors, namely, the strength of RPC and steel tube and the diameter-thickness ratio. Finally, a comparative analysis of 180 RFCT columns axial compressive tests is conducted to propose a calculation formula of axial compressive strength of RFCT columns.

\section{Experimental Program}

2.1. Test Specimens. Thirteen RFCT columns were tested, out of which six columns were tested under cyclic axial compressive load, and seven columns were tested under monotonic axial load. As shown in Table 1, the columns were classified into two groups, namely, group-c for columns with cyclic loading and group-m for columns with monotonic loading. The diameter of the seamless steel tube in the specimens was $219 \mathrm{~mm}, 245 \mathrm{~mm}$, or $273 \mathrm{~mm}$. In order to investigate the mechanical properties of RFCT columns subjected to axial load and to prevent significant flexural deformation, the length-to-diameter ratio was maintained as 3. While this ratio is relatively small when compared to the ratio in actual structural columns, a smaller ratio was chosen to eliminate any likely effect of column buckling in the experiments [24-26]. The yield strength of tube steel $\left(f_{\mathrm{y}}\right)$ was determined by testing standard tensile strength specimens which were cut from each tube. The RPC infill in all tubes had the same mixture proportion and was subjected to identical steam curing regime. The RFCT column specimens were stored at room temperature for 48 hours after pouring 
TABLE 1: Summary of test parameters of columns.

\begin{tabular}{|c|c|c|c|c|c|c|c|c|c|c|c|}
\hline Group & Specimen & $D \times t \times L(\mathrm{~mm})$ & $D / t$ & $\xi$ & $f_{\mathrm{y}}(\mathrm{MPa})$ & $f_{\mathrm{cu}}(\mathrm{MPa})$ & $N_{\mathrm{ue}}(\mathrm{kN})$ & $N_{\mathrm{u} 1}(\mathrm{kN})$ & $N_{\mathrm{u} 2}(\mathrm{kN})$ & $N_{\mathrm{ue}} / N_{\mathrm{u} 1}$ & $N_{\mathrm{ue}} / N_{\mathrm{u} 2}$ \\
\hline \multirow{6}{*}{ Group-c } & c-219-8 & $219 \times 8 \times 657$ & 27.4 & 0.74 & 450 & 118 & 6238 & 5620 & 6401 & 1.11 & 0.97 \\
\hline & $c-219-10$ & $219 \times 10 \times 657$ & 21.9 & 0.91 & 430 & 118 & 6632 & 5930 & 6852 & 1.12 & 0.97 \\
\hline & c-219-12 & $219 \times 12 \times 657$ & 18.3 & 0.98 & 375 & 118 & 7009 & 5909 & 6879 & 1.18 & 1.02 \\
\hline & c-245-8 & $245 \times 8 \times 735$ & 30.6 & 0.62 & 425 & 118 & 7237 & 6646 & 7488 & 1.09 & 0.97 \\
\hline & $c-245-12$ & $245 \times 12 \times 735$ & 20.4 & 0.88 & 383 & 118 & 8407 & 7196 & 8321 & 1.17 & 1.01 \\
\hline & c-273-10 & $273 \times 10 \times 819$ & 27.3 & 0.63 & 381 & 118 & 9025 & 8171 & 9243 & 1.10 & 0.98 \\
\hline \multirow{7}{*}{ Group-m } & $\mathrm{m}-219-8$ & $219 \times 8 \times 657$ & 27.4 & 0.74 & 450 & 118 & 6120 & 5620 & 6401 & 1.10 & 0.96 \\
\hline & $m-219-10$ & $219 \times 10 \times 657$ & 21.9 & 0.91 & 430 & 118 & 6456 & 5930 & 6852 & 1.09 & 0.94 \\
\hline & $m-219-12$ & $219 \times 12 \times 657$ & 18.3 & 0.98 & 375 & 118 & 6803 & 5909 & 6879 & 1.15 & 0.99 \\
\hline & $\mathrm{m}-245-8$ & $245 \times 8 \times 735$ & 30.6 & 0.62 & 425 & 118 & 7207 & 6646 & 7488 & 1.08 & 0.96 \\
\hline & $\mathrm{m}-245-12$ & $245 \times 12 \times 735$ & 20.4 & 0.88 & 383 & 118 & 7883 & 7196 & 8321 & 1.09 & 0.95 \\
\hline & $\mathrm{m}-273-8$ & $273 \times 8 \times 819$ & 34.1 & 0.53 & 412 & 118 & 8260 & 7927 & 8844 & 1.04 & 0.93 \\
\hline & $m-273-10$ & $273 \times 8 \times 819$ & 27.3 & 0.63 & 381 & 118 & 8892 & 8171 & 8583 & 1.09 & 1.04 \\
\hline
\end{tabular}

and then were cured under steam at $90^{\circ} \mathrm{C}-95^{\circ} \mathrm{C}$ for 72 hours. The strength of RPC was determined by testing $70.7 \mathrm{~mm}$ size cube specimens $\left(f_{\mathrm{cu}}\right)$, which were cured under the same condition as for RFCT columns. The cylinder strength of concrete was estimated as $f_{\mathrm{c}}=0.845 f_{\mathrm{cu}}$ [27]. The measured elastic modulus $(E c)$ of RPC was $45 \mathrm{GPa}$. A summary of the critical test parameters of the test columns is tabulated in Table 1 .

(1) In the nomenclature of groups, group-c means specimens were subjected to cyclic compressive load, while group-m means specimens were subjected to monotonic compressive load.

(2) In the nomenclature of specimens, for example c-219-8, the first letter "c" represents cyclic axial compression; the second number " 219 " represents the diameter $D$ of the steel tube; and the third number " 8 " represents the thickness of the steel tube.

(3) Parameters in this table include the diameter of steel tube $D$; the thickness of steel tube $t$; the length of RFCT columns $L$; the yield strength of steel tube $f_{\mathrm{y}}$; the $70.7 \mathrm{~mm}$ cube compressive strength of RPC $f_{\mathrm{cu}}$; the cross-sectional area of steel tube $A_{\mathrm{s}}$; the crosssectional area of RPC $A_{\mathrm{c}}$; and the confinement coefficient of RFCT columns $\xi\left(\xi=A_{\mathrm{s}} f_{\mathrm{y}} / A_{\mathrm{c}} f_{\mathrm{c}}\right)$.

(4) $N_{\mathrm{ue}}$ is the axial compressive strength from experiment; $N_{\mathrm{u} 1}$ is the calculated capacity from equation (8); and $N_{\mathrm{u} 2}$ is the calculated capacity from equation (9).

2.2. Material Properties of RPC. The ingredients and mixture ratio of RPC are listed in Table 2. Cement used was ordinary Portland cement (OPC) of strength class 52.5 MPa. Fine quartz sand, with $\mathrm{SiO}_{2}$ content of more than $99.6 \%$, was used with particle size ranging from $0.18 \mathrm{~mm}$ to $0.6 \mathrm{~mm}$. Silica fume was used with $\mathrm{SiO}_{2}$ content of $95 \%$ and particle size ranging from $0.1 \mu \mathrm{m}$ to $0.2 \mu \mathrm{m}$. Moreover, slag with $\mathrm{SiO}_{2}$ content of $34.90 \%$ and high consistency naphthalene water reducer (FDN) were used in the RPC mixture. Brass-coated steel fibers (elastic modulus and tensile strength of steel fibers were $200 \mathrm{GPa}$ and $2250 \mathrm{MPa}$ ) with diameter of $0.22 \mathrm{~mm}$ and length of $13 \mathrm{~mm}$ on an average were embedded to improve the strength and ductility.

2.3. Test Setup and Instrumentation. The RFCT column specimens were tested using a $10,000 \mathrm{kN}$ hydraulic compressive testing machine, as illustrated in Figure 2. The RFCT columns in group-m were subjected to monotonic load. Load control with a load increment of $10 \%$ ultimate load was adopted until the load reached $70 \%$ of the estimated ultimate load. After that, a displacement control mode was adopted. In order to ensure that specimens were loaded concentrically, specimens were properly checked and leveled before testing. The rate of load control $\left(R_{\mathrm{L}}\right)$ was maintained to have a stress rate of $0.06 \mathrm{MPa} / \mathrm{s}$, and the rate of displacement control $\left(R_{\mathrm{d}}\right)$ was maintained to have a strain rate of $10 \mu \varepsilon / s$.

Specimens in group-c were tested following a cyclic loading program, as illustrated in Figure 3. Multistage loading was adopted. The increment in each step was $50 \%$ of the calculated capacity $N_{\mathrm{u} 1}$, and one loading cycle was applied for each step. After yielding, the loading procedure was changed to displacement control mode. The incremental displacement in each step was $2 \Delta_{\mathrm{y}}$ (where $\Delta_{\mathrm{y}}$ is the displacement corresponding to the calculated capacity $N_{\mathrm{u} 1}$ ), and two cycles were applied for each step. In order to ensure that specimens were loaded concentrically, the top surface was leveled by plastering before testing. The rates of load and displacement control for group-c specimens were same as for group-m specimens.

Six linear displacement transducers (LVDTs) were used to measure the axial deformation of the stub column specimens. Out of them, four LVDTs (range: $\pm 25 \mathrm{~mm}$, precision: $0.01 \mathrm{~mm}$ ) were used to measure the deformation of the middle third of the stub columns, and two LVDTs (range: $\pm 250 \mathrm{~mm}$, precision:0.01 $\mathrm{mm}$ ) were used to measure the total deformation. Four longitudinal and four hoop strain gauges were placed vertically at the middle part of each column. Figure 2 illustrates the details of LVDTs and strain gauges. 
TABLE 2: RPC mix proportion.

\begin{tabular}{|c|c|c|c|c|c|c|c|c|}
\hline $\begin{array}{l}\text { Total mass without } \\
\text { fiber }(\mathrm{kg})\end{array}$ & Cement (kg) & $\begin{array}{c}\text { Silica } \\
\text { fume }(\mathrm{kg})\end{array}$ & Slag (kg) & Quartz sand (kg) & FDN (kg) & Water $(\mathrm{kg})$ & Steel fiber (kg) & Water/binder ratio \\
\hline 2400.00 & 800.53 & 240.16 & 120.08 & 960.64 & 46.43 & 232.15 & 156.00 & 0.22 \\
\hline
\end{tabular}

Note. Water/binder ratio is the weight of water to the combined weight of cement, silica fume, and slag.

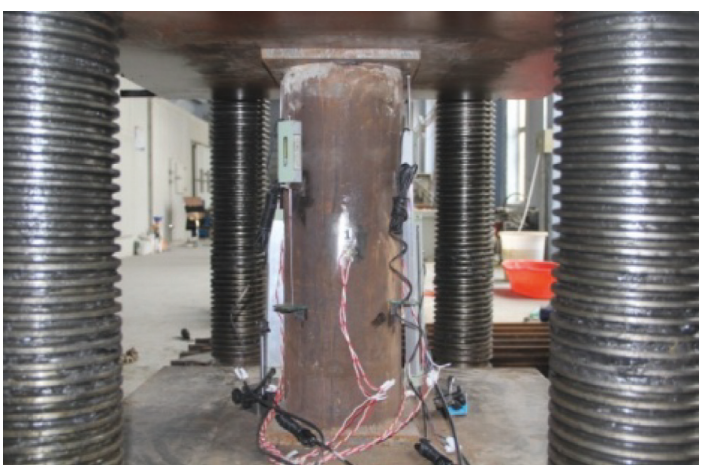

(a)

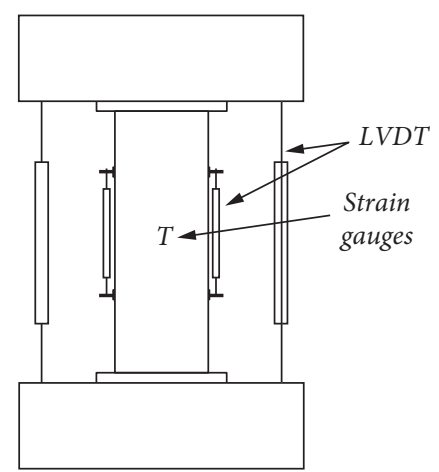

(b)

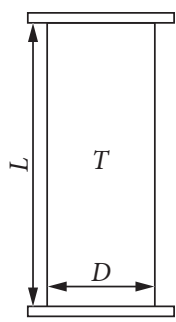

Figure 2: Test setup and instrumentation of stub columns.

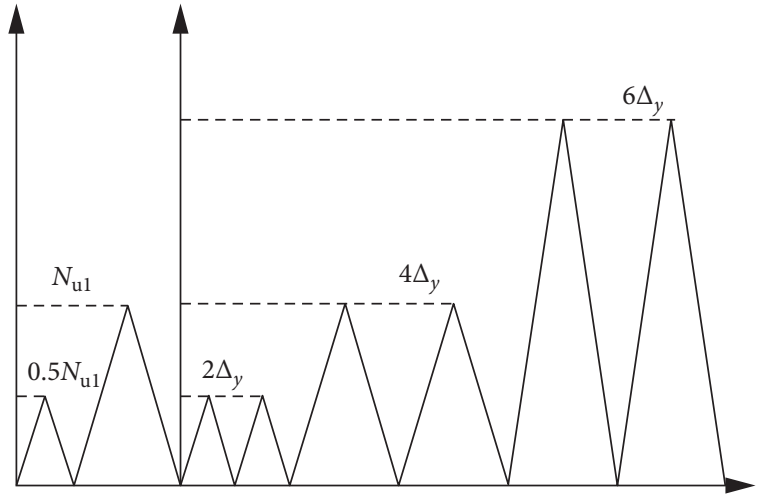

Figure 3: Cyclic loading program of stub columns of group-c.

\section{Test Results of RFCT Columns}

3.1. Failure Mode of RFCT Columns. Generally, all specimens in group-c showed similar failure process. The confinement coefficient had a significant influence on the failure modes of RFCT stub columns. For the confinement coefficient in the range of 0.53 to 0.98 , the failure mode of specimens under cyclic loading was shear failure. The shape of steel tube was not changed when the load was under elastic range. RPC behaved as a homogeneous elastic material which has a small coefficient of lateral deformation. Figure 4 shows the failure mode of RFCT columns in group-c. It was observed that stub columns with the lower confinement coefficient $(\xi<0.8)$ exhibited severe share failure. On the shear slip plane, steel fibers were pulled out and the RPC was crushed. The shear failure in other stub columns $(\xi \geq 0.8)$ was relatively slight as shown in Figures 4(c) and 4(f). This was because steel tube provided relatively stronger constraint in those columns. With an increase in confinement coefficient, the failure mode transformed from shear failure to compressive failure for specimens under monotonic load.
Specimens in group-m showed different failure modes when compared to group-c specimens. The failure mode of specimens with lower confinement coefficient $(\xi<0.8)$ was shear failure. However, when the confinement coefficient exceeded $0.9(\xi \geq 0.8)$, the specimens exhibited local buckling failure. It is concluded that with an increase in confinement coefficient, the restraining effect of steel tube increased which contributed in reducing shear failure. This observation indicates that if the confinement coefficient of stub columns is large enough, shear failure can be completely avoided. The confinement stress affecting the failure modes is mainly because the core RPC is under triaxial compressive in RPCT columns; with the increase of compressive stress, the hoop stress increases. Then, the shear failure mode occurred at the section where shear capacity is lower [28]. As compared with normal strength of concretefilled steel tubes, the shear failure is more susceptible to occur in high-strength concrete and RPC-filled steel tubes. However, if the confinement coefficient is higher enough, the hoop stress provided by the steel tube is higher, and the failure mode changed from shear failure to compressive failure.

The shear angle $(\beta)$ of RPC core was measured and found to lie between $55^{\circ}$ and $70^{\circ}$. As in the case of circular steel tube filled with normal strength concrete (NSC), shear angle $\beta$ of RPC can be calculated by Mohr-Coulomb theory as

$$
\beta=45^{\circ}+\frac{\phi}{2}
$$

where $\phi$ is the internal friction angle of (RPC) concrete. $\beta$ of ordinary concrete prism is $\beta=58^{\circ} \sim 64^{\circ}$, and $\beta$ of HSC-filled tube columns is $\beta=57^{\circ} \sim 65^{\circ}$ [28]. The test results demonstrated that the shear angle of RFCT columns satisfied Mohr-Coulomb theory. The influence of shear angle of RPC on the strength of RFCT columns needs further research. 


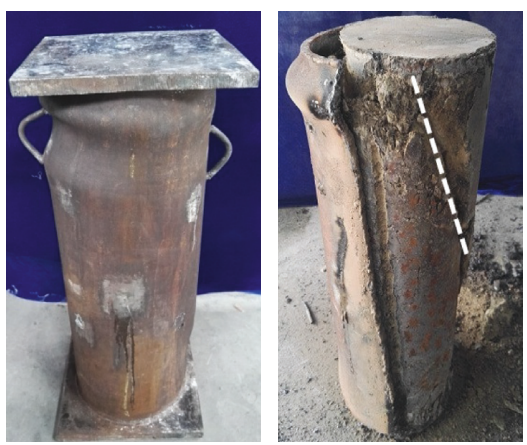

(a)
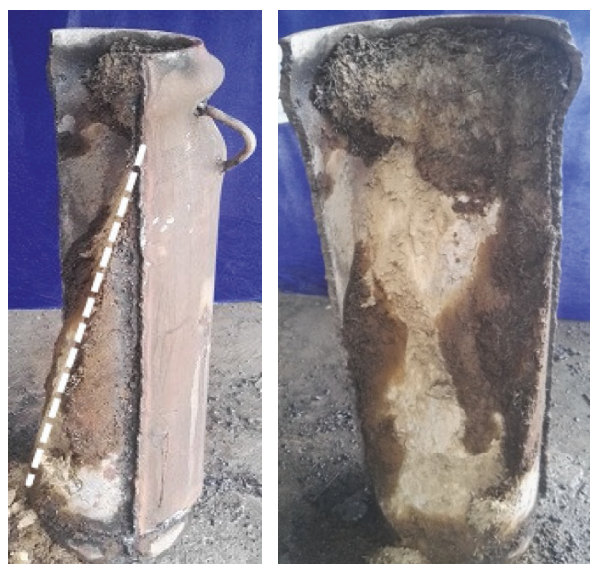

(d)

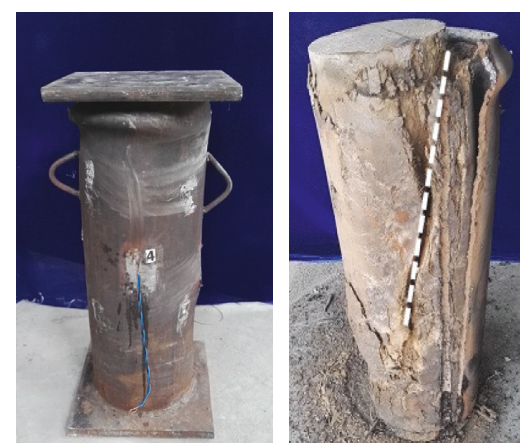

(b)
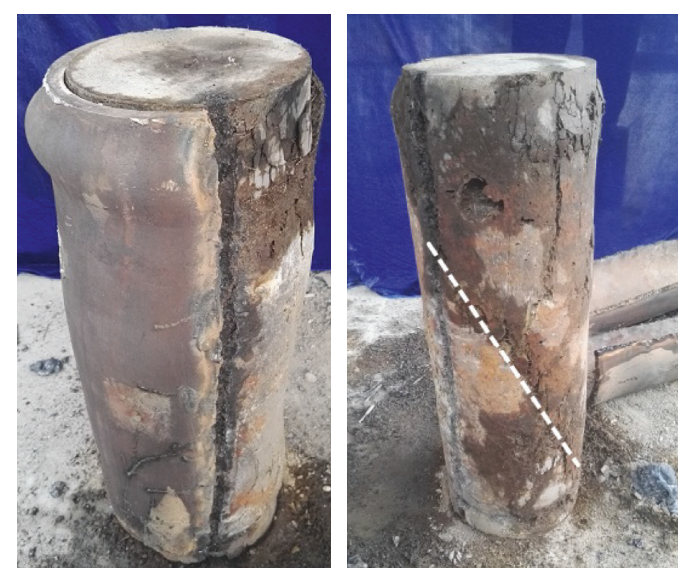

(e)
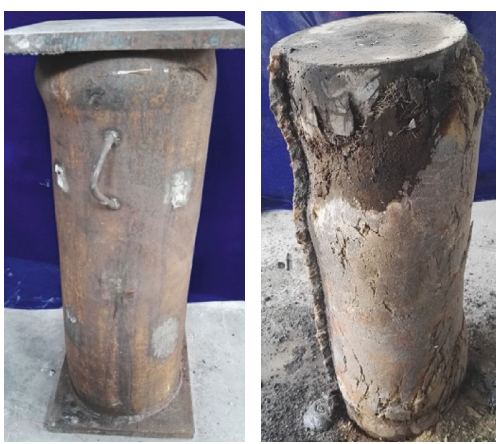

(c)

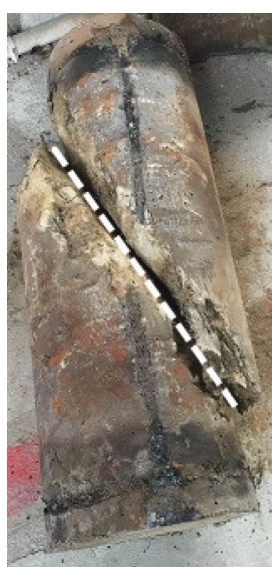

(f)

Figure 4: Failure modes of group-c specimens. (a) c-219-8 (shear failure). (b) c-219-10 (shear failure). (c) c-219-12 (compressive failure). (d) c-245-8 (shear failure). (e) c-245-12 (shear failure). (f) c-273-10 (compressive failure).

\subsection{Load-Axial Strain Relationship of RFCT Columns.} Load-axial strain relationships of RFCT columns are shown in Figure 5, where $\varepsilon=\Delta / L$ ( $\Delta$ is the total axial deformation monitored by LVDTs and $L$ is the length of the stub column specimens). All stub columns exhibited excellent ductility. For the specimens under cyclic axial load, the loadingunloading curves basically coincided confirming that the unloading process was elastic. Furthermore, as compared with the specimens under monotonic loading with the same cross section, the envelope curves of specimens under cyclic loading showed a good agreement with the loaddeformation curves of the specimens under monotonic loading. With the increase of loading cycles, the deformation of specimens is increased. At the beginning of unloading stage, the axial load dropped sharply with little deformation restored. When unloaded completely, the residual deformation existed and accumulated with the development of plastic strain. Besides, the unloading stiffness and reloading stiffness remains similar as the loading stiffness.

Figure 6 compares the envelope curves and unitary envelope curves of RFCT columns, where $N_{\mu}$ is the peak load and $\varepsilon_{\mu}$ is the strain corresponding to the peak load. For a given cross section and for a given loading program, the axial compressive strength of RFCT columns increased with an increase in the confinement coefficient and with a decrease in the diameter-to-thickness ratio. After the peak load, the compressive strength of specimens in group-c decreased gradually until the compressive strength reduced to $80 \%-90 \%$ of the peak load. Then, the bearing capacity of RFCT columns increased again, though slowly, exhibiting the strain-hardening phenomenon in the RFCT columns.

\section{Stress-Strain Analysis of RFCT Columns}

4.1. Strain Analysis of Steel Tube. The envelope curves of load-strain relationship and the variation of the ratio of hoop strain and longitudinal strain are shown in Figure 7 , where $\varepsilon_{\mathrm{hc}}$ and $\varepsilon_{\mathrm{vc}}$ are, respectively, the hoop strain and longitudinal stress at the midheight of steel tube in group-c and $\varepsilon_{\mathrm{hm}}$ and $\varepsilon_{\mathrm{vm}}$ are, respectively, the hoop strain and longitudinal stress of steel tube in group- $m$. The yield point of the RFCT columns is shown in Figure 7, and the specimens yielded before the peak load point. von Mises yield criterion was adopted to define the yield point of the stub specimens as

$$
\sqrt{\sigma_{\mathrm{v}}^{2}+\sigma_{\mathrm{h}}^{2}-\sigma_{\mathrm{v}} \sigma_{\mathrm{h}}}=f_{\mathrm{y}}
$$

where $\sigma_{\mathrm{v}}$ and $\sigma_{\mathrm{h}}$ are the longitudinal and hoop stresses of the steel tube and can be obtained by the following equations [15]: 

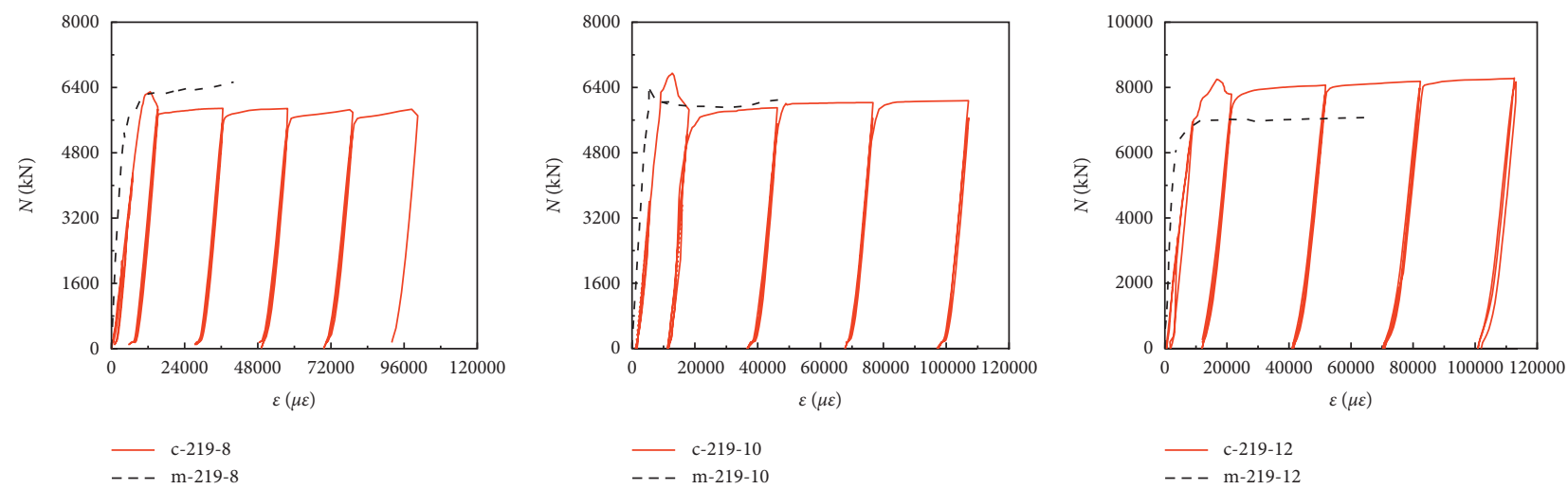

(a)

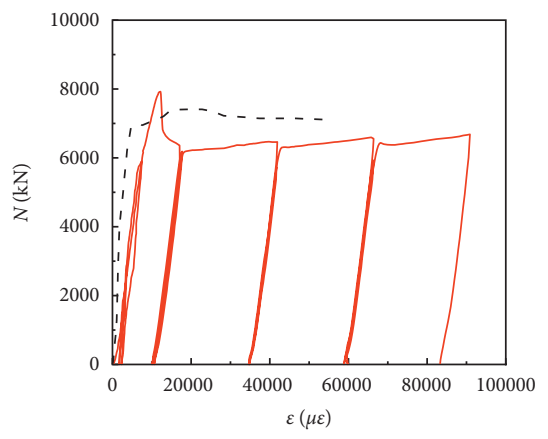

(b)

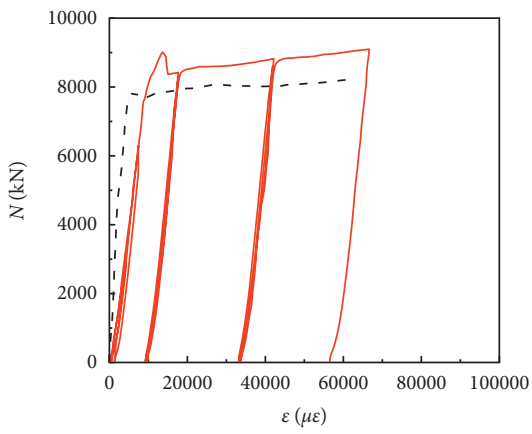

(c)

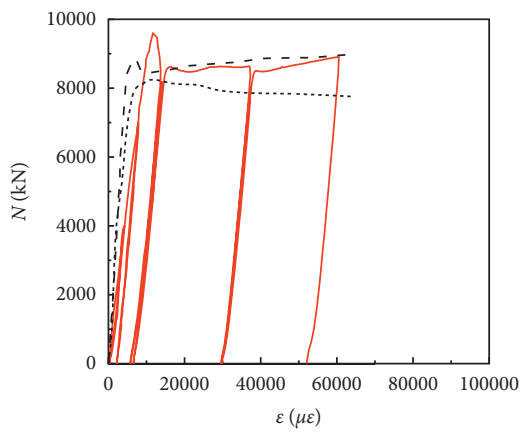

\begin{tabular}{ll} 
& c-245-8 \\
\hline-- & m-245-8
\end{tabular}

- c-245-12

— c-273-10

- - $\mathrm{m}-273-10$

m-273-8

(d)

(e)

(f)

FIGURE 5: Load-strain curves of RFCT columns (for column designations, refer Table 1). (a) 219-8. (b) 219-10. (c) 219-12. (d) 245-8. (e) 245-12. (f) 273-8/10.

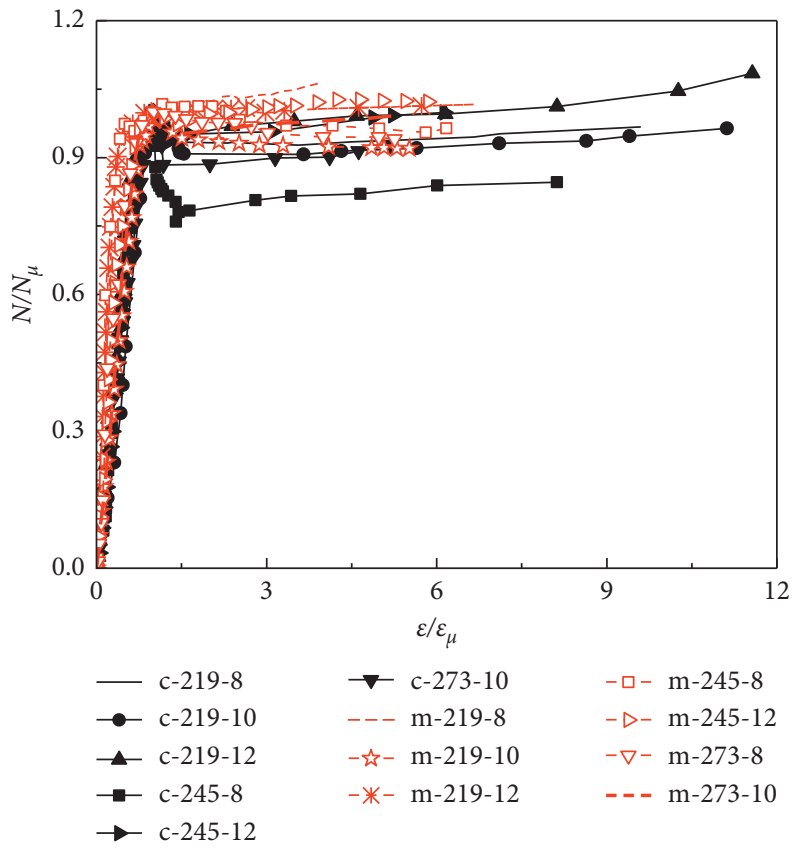

FIGURE 6: Comparison of envelope curves and unitary envelope curves of RFCT columns. 

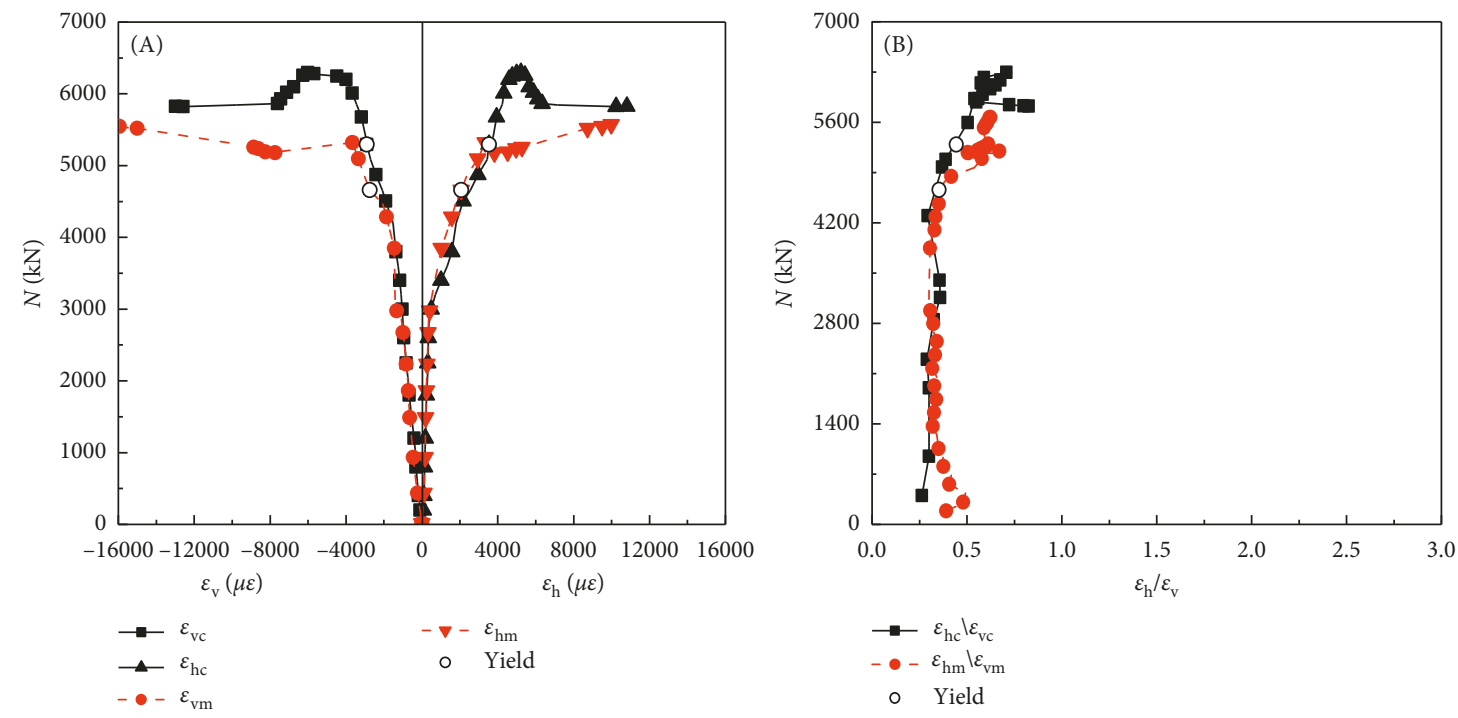

(a)
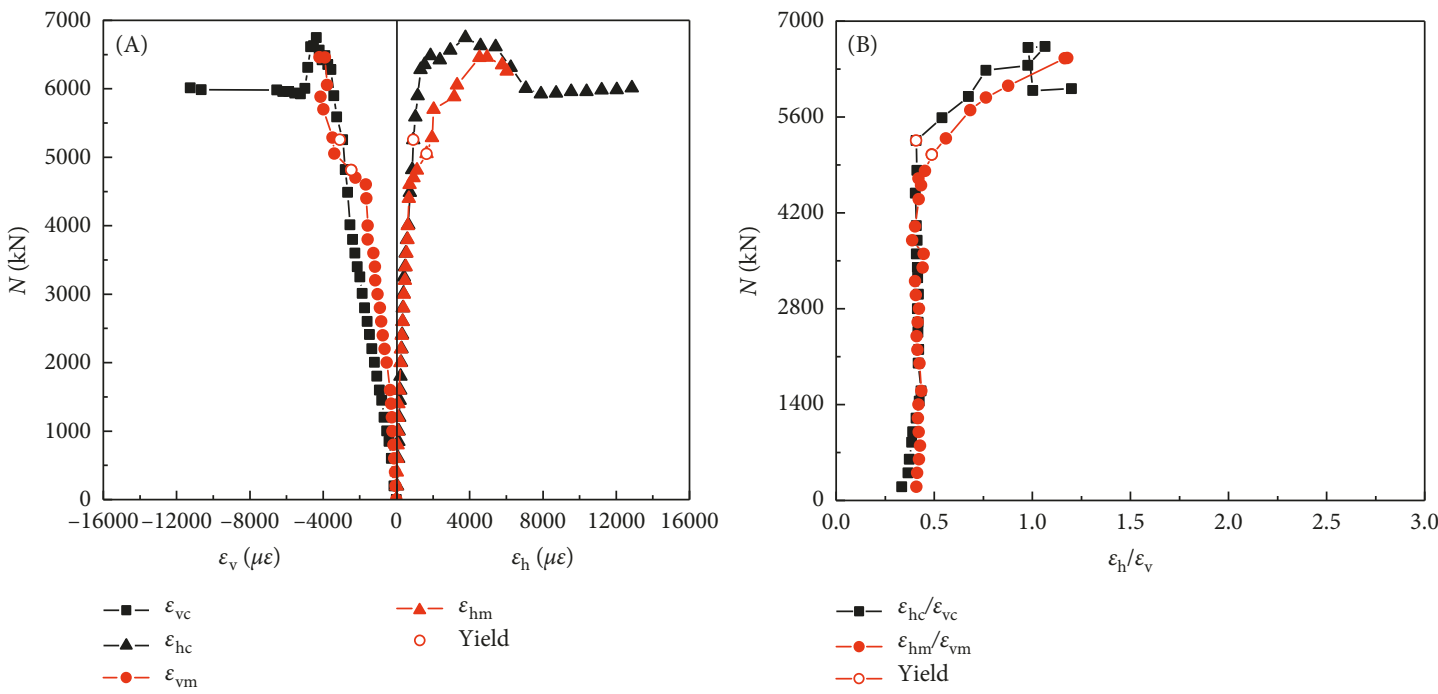

(b)
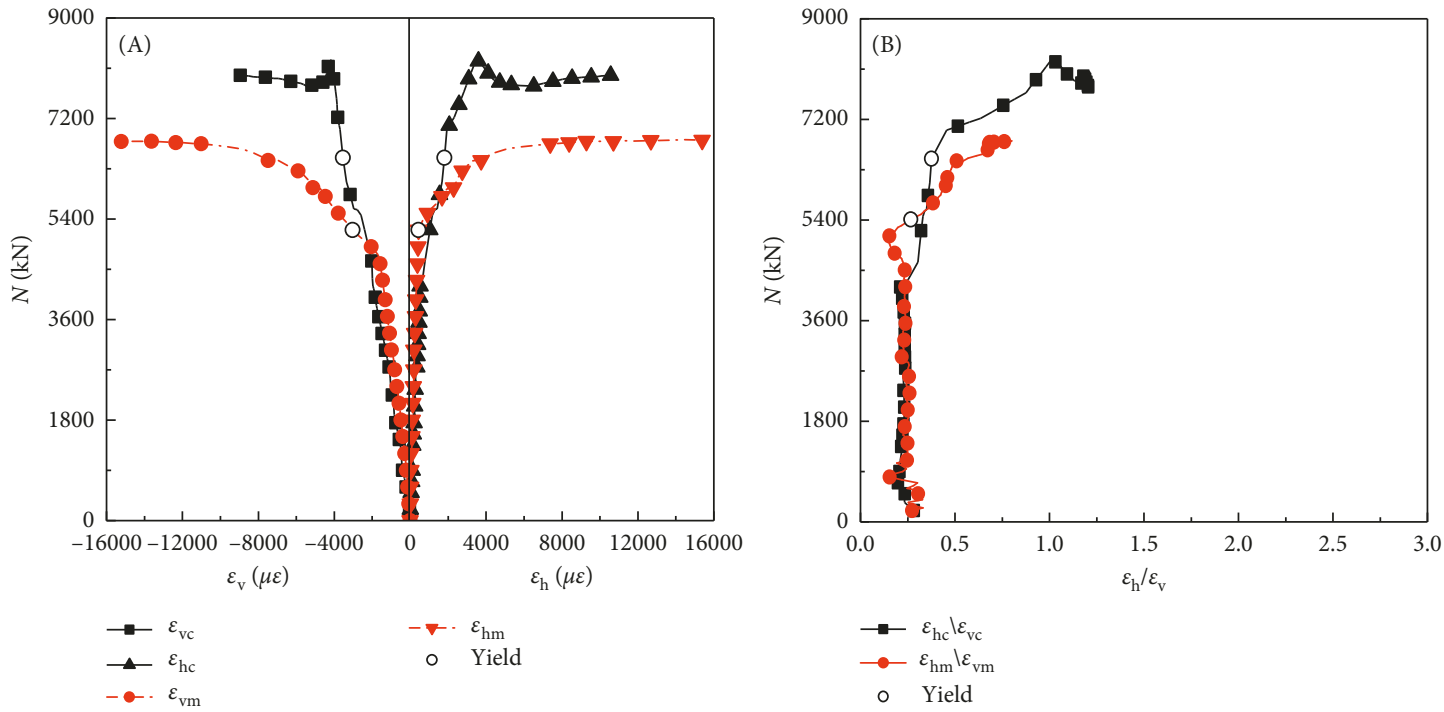

(c)

Figure 7: Continued. 

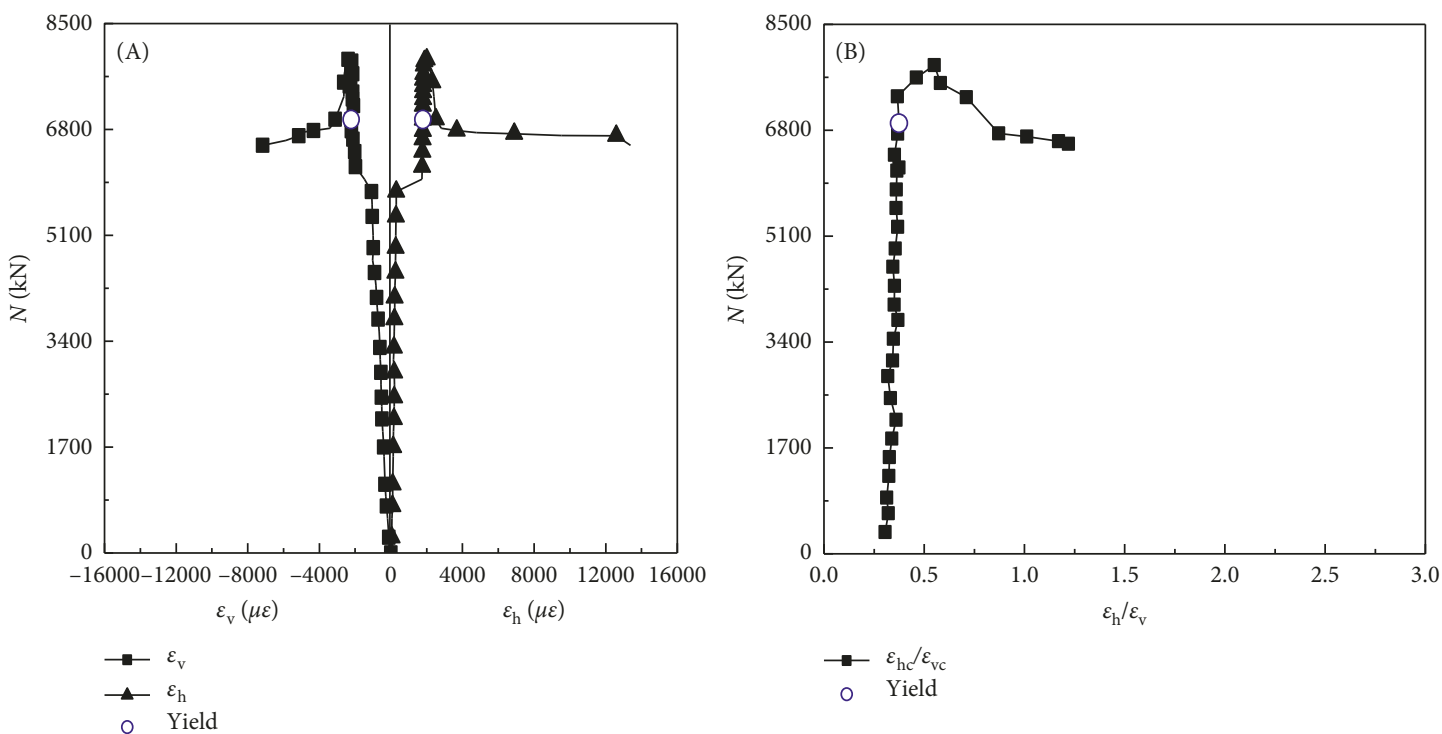

(d)
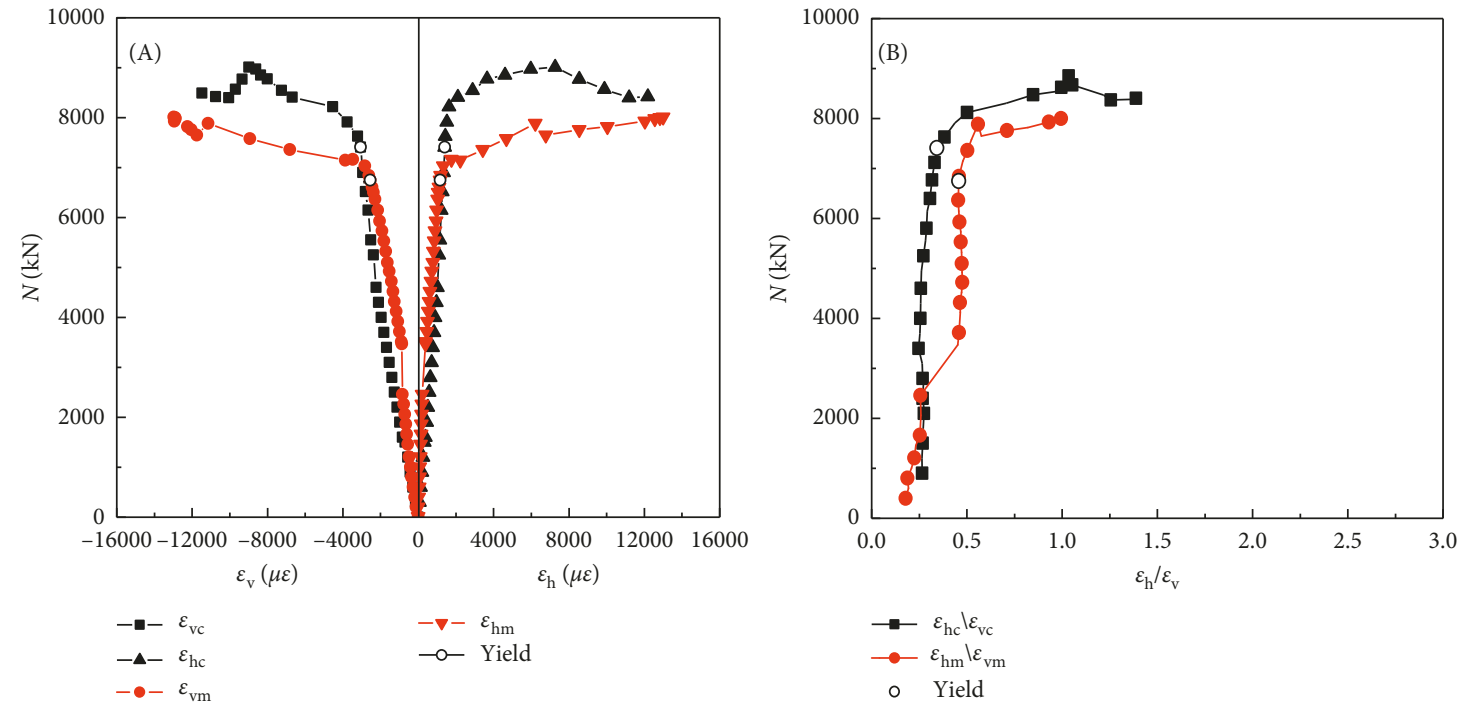

(e)
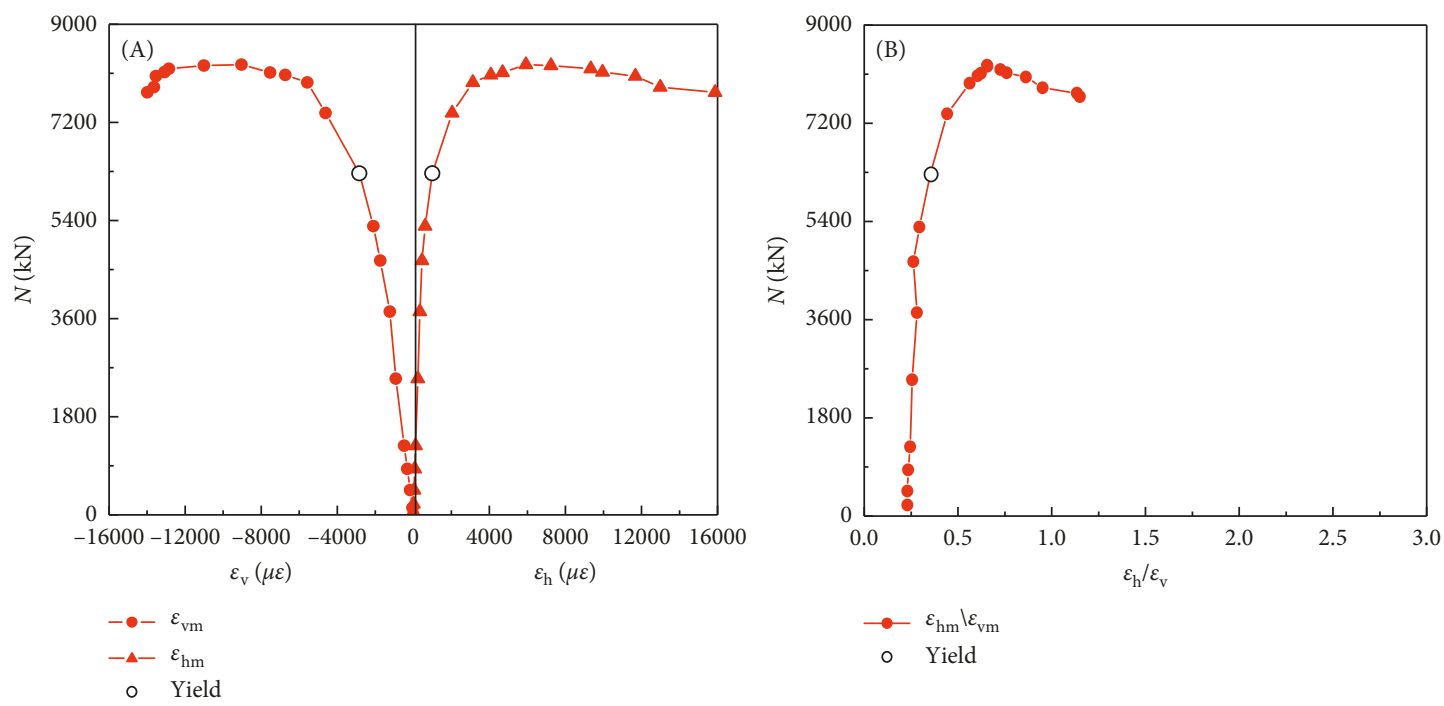

(f)

Figure 7: Continued. 

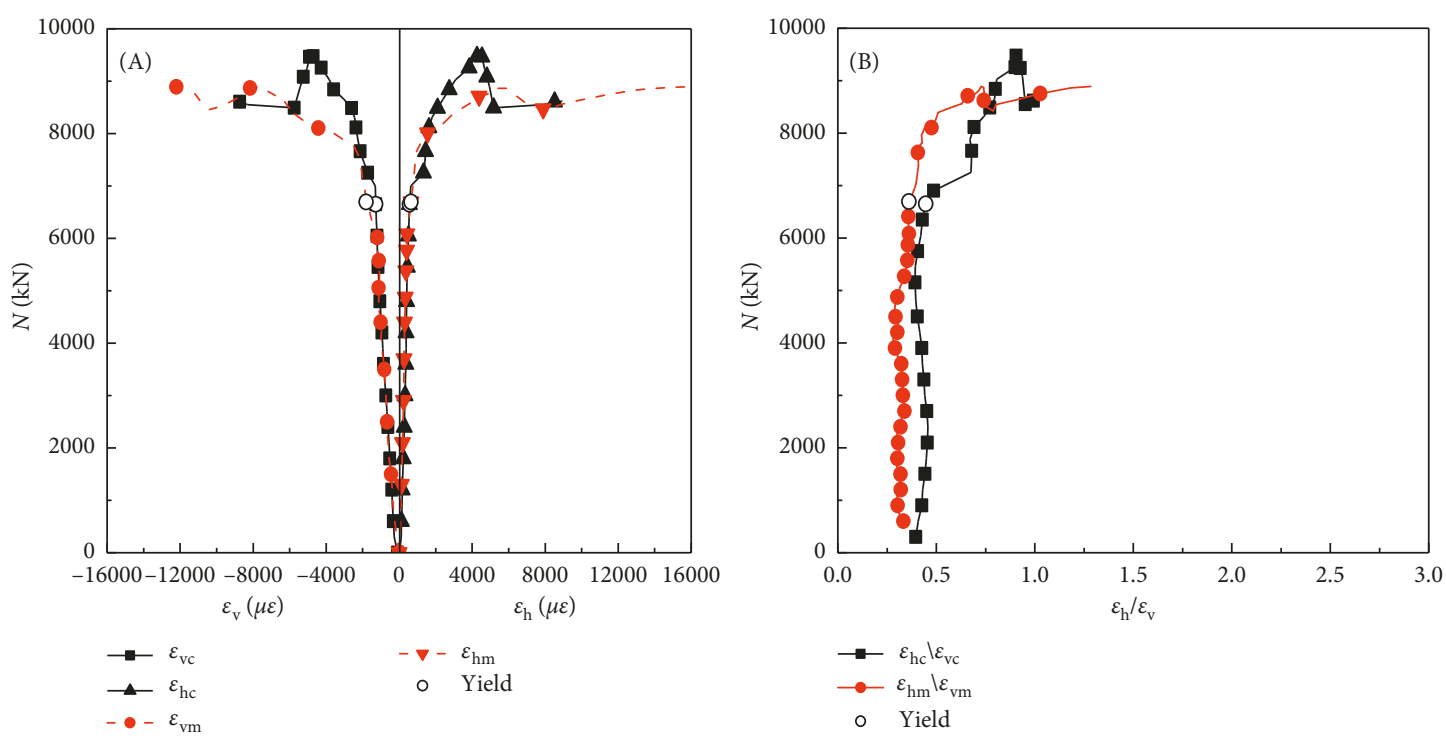

(g)

FiguRE 7: Strain analysis results on the steel tube of group-c specimens. Envelope curves of (A) load vs. strain and (B) load vs. $\varepsilon_{\mathrm{h}} / \varepsilon_{\mathrm{v}}$ for (a) 219-8, (b) 219-10, (c) 219-12, (d) 245-8, (e) 245-12, (f) 273-8, and (g) 273-10.

$$
\begin{gathered}
\sigma_{\mathrm{v}}=\left(\frac{E_{\mathrm{s}}}{1-v_{\mathrm{s}}^{2}}\right) \varepsilon_{v}+\left(\frac{E_{\mathrm{s}} v_{\mathrm{s}}}{1-v_{\mathrm{s}}^{2}}\right) \varepsilon_{\mathrm{h}}, \\
\sigma_{\mathrm{h}}=\left(\frac{E_{\mathrm{s}}}{1-v_{\mathrm{s}}^{2}}\right) \varepsilon_{h}+\left(\frac{E_{\mathrm{s}} v_{\mathrm{s}}}{1-v_{\mathrm{s}}^{2}}\right) \varepsilon_{\mathrm{v}},
\end{gathered}
$$

where $E_{\mathrm{s}}$ and $v_{\mathrm{s}}$ are the elastic modulus and Poisson's ratio of RFCT columns and $\varepsilon_{\mathrm{v}}$ and $\varepsilon_{\mathrm{h}}$ are the longitudinal and hoop strains of the steel tube, respectively.

In the experiment, the longitudinal strain developed faster than the hoop strain in the elastic stage. The $\varepsilon_{\mathrm{h}} / \varepsilon_{\mathrm{v}}$ ratio was in the range of 0.28 to 0.36 and was approximately equal to Poisson's ratio of steel. This means steel tubes did not provide confining effect to the RPC in the elastic stage. However, with an increase in the axial stress, the longitudinal strain was exceeded by the hoop strain because of the rapid lateral expansion of the RPC, and the value of $\varepsilon_{\mathrm{h}} / \varepsilon_{\mathrm{v}}$ increased as well. The confining force was effective only after the elastic stage.

The lateral deformation coefficient $(v)$ of concrete varied with compressive strength as shown in Figure 8, where $\sigma$ and $f_{\mathrm{c}}$ are the external load and compressive strength of concrete, respectively. The lateral deformation coefficients varied with concrete strength as listed in Table 3 . Results showed that the lateral deformation coefficient increased with an increase in the load level ( $\sigma$ varied from $0.2 f_{\mathrm{c}}$ to $0.9 f_{\mathrm{c}}$ ) $[29,30]$. It was observed that when $\sigma=0.2 f_{\mathrm{c}}$ and $\sigma=0.6 f_{\mathrm{c}}$, concrete was in the elastic stage; thus, three types concrete (NSC, HSC, and RPC) had similar coefficient, with the mean value of the coefficient as $v=0.204$. However, when load level reached to $0.8 f_{c}$, microcracks were formed and propagated in concrete. Since most cracks were parallel to the stress direction, the width and number of microcracks caused the evolution of lateral deformation. The coefficient $v$ increased the most for NSC, but the coefficient increased the least for RPC. This phenomenon became more obvious when $\sigma=f_{\mathrm{c}}$. As shown in Figure 8(d), NSC had a large lateral deformation, and the coefficient was up to 0.57 . As compared to NSC, the lateral deformation of HSC and RPC increased slowly. The coefficient of HSC ranged from 0.26-0.36, and the coefficient of RPC was between 0.25 and 0.31 . This is mainly because the development of microcracks in RPC is lower than that in HSC and NSC at the same load level [31]. This suggests that concrete with higher compressive strength has a lower lateral deformation coefficient. The core concrete with a large lateral deformation coefficient can obtain more confining effect, and in that sense, confinement effect of steel tube is not as pronounced in RPC infill as with NSC infill.

4.2. Stress-Strain Analysis of RFCT Columns. Based on the elastic-plastic analytical method [15, 28], a stress-strain analysis was conducted for RFCT column specimens. Plane stress-strain relationship of steel tube was adopted to evaluate the stress level of steel tube and RPC under axial load. Figure 9 illustrates the stress-strain analysis results of RFCT columns, including the envelope curves of load vs. stress in steel tube and the envelope curves of stress vs. strain in RPC. In the figure, $\sigma_{\mathrm{vc}}, \sigma_{\mathrm{hc}}$, and $\sigma_{\mathrm{zm}}$ are, respectively, the longitudinal, hoop, and equivalent stresses of group-c specimens, and $\sigma_{\mathrm{vm}}$, $\sigma_{\mathrm{hm}}$, and $\sigma_{\mathrm{zm}}$ are, respectively, the longitudinal, hoop, and equivalent stresses of group-m. Similarly, $\sigma_{\mathrm{cc}}$ and $\sigma_{\mathrm{cm}}$ are compressive stresses in RPC in group-c and group-m specimens, and $\varepsilon$ is the strain of the stub columns. The equivalent stress $\sigma_{\mathrm{z}}$ can be calculated by the following equation:

$$
\sigma_{\mathrm{z}}=\frac{\sqrt{2}}{2} \sqrt{\left(\sigma_{\mathrm{v}}-\sigma_{\mathrm{h}}\right)^{2}+\sigma_{\mathrm{v}}^{2}+\sigma_{\mathrm{h}}^{2}}
$$

Stress results show that steel tube yielded before the stub columns reached the peak pressure. Hoop stress grew slowly and remained at a low level, which implies that the yielding of 


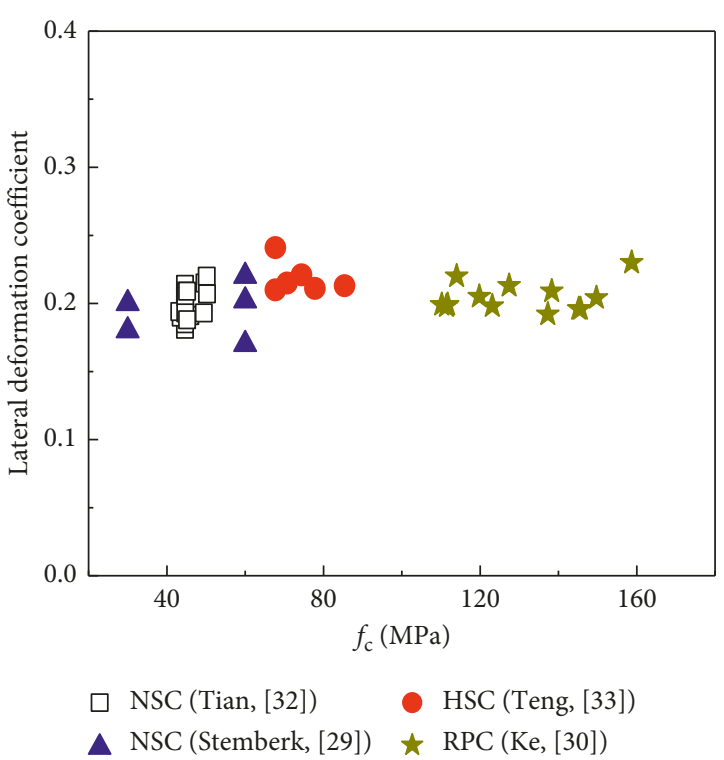

(a)

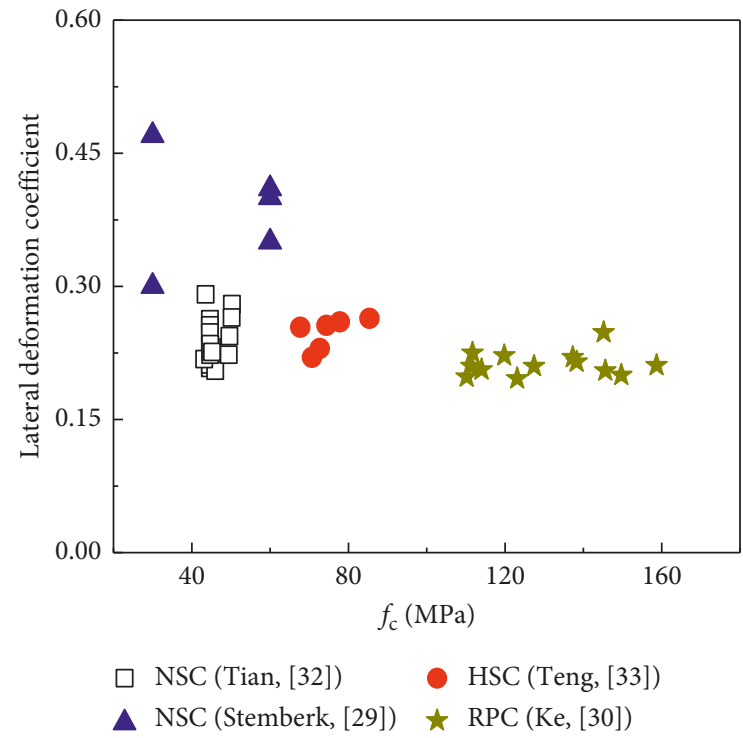

(c)

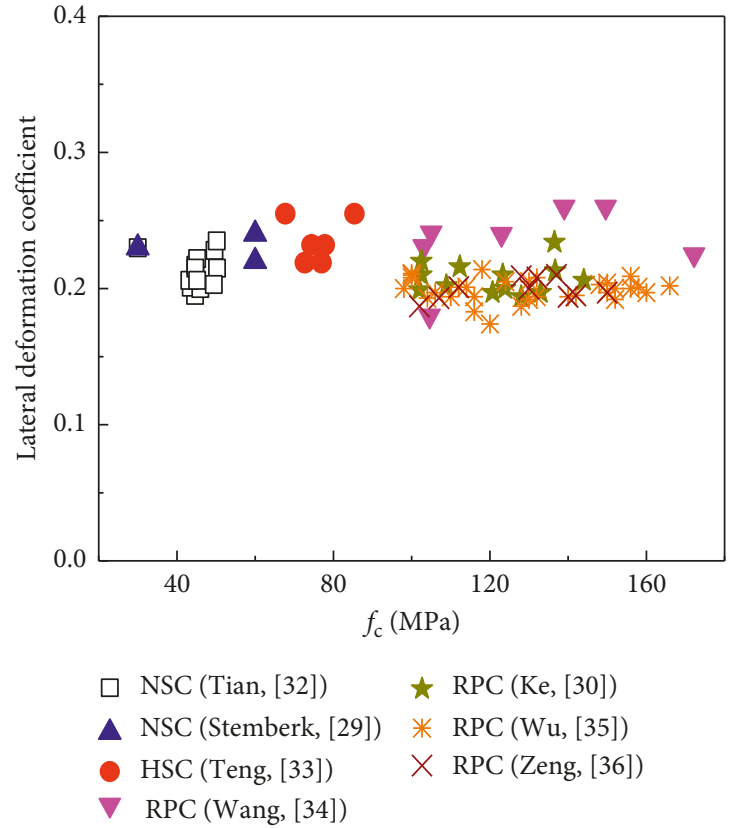

(b)

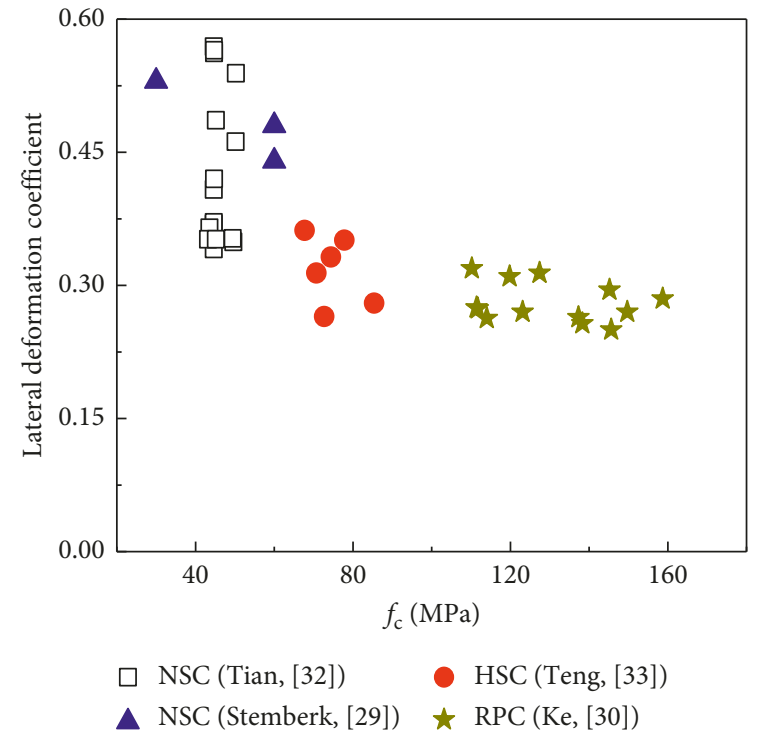

(d)

Figure 8: Lateral deformation coefficient of concrete for different strengths and different load levels. (a) $\sigma=0.2 f_{\text {c. }}$ (b) $\sigma=0.6 f_{c}$. (c) $\sigma=0.8 f_{\text {c }}$. (d) $\sigma=f_{\text {c }}$.

TABLE 3: The lateral deformation coefficient of concrete with different strengths.

\begin{tabular}{|c|c|c|c|c|c|}
\hline \multirow{2}{*}{ Concrete } & \multirow{2}{*}{ Compressive strength (MPa) } & \multicolumn{4}{|c|}{ Load level } \\
\hline & & $0.2 f_{\mathrm{c}}$ & $0.6 f_{\mathrm{c}}$ & $0.8 f_{\mathrm{c}}$ & $f_{\mathrm{c}}$ \\
\hline NSC & $30-60$ & $0.17-0.22$ & $0.19-0.26$ & $0.22-0.47$ & $0.22-0.57$ \\
\hline HSC & $60-100$ & $0.18-0.24$ & $0.19-0.25$ & $0.22-0.25$ & $0.26-0.36$ \\
\hline PRC & $100-170$ & $0.17-0.24$ & $0.19-0.25$ & $0.22-0.25$ & $0.25-0.31$ \\
\hline
\end{tabular}

Note. $f_{\mathrm{c}}$ is the compressive strength of concrete.

steel tube was essentially caused by the growth of the longitudinal stress. After the yield point, the hoop stress gradually increased, while there was a decreasing trend for the longitudinal stress. This is because the transverse deformation of RPC increased sharply during plastic stage and the confining stress provided by the steel tube increased. Therefore, 

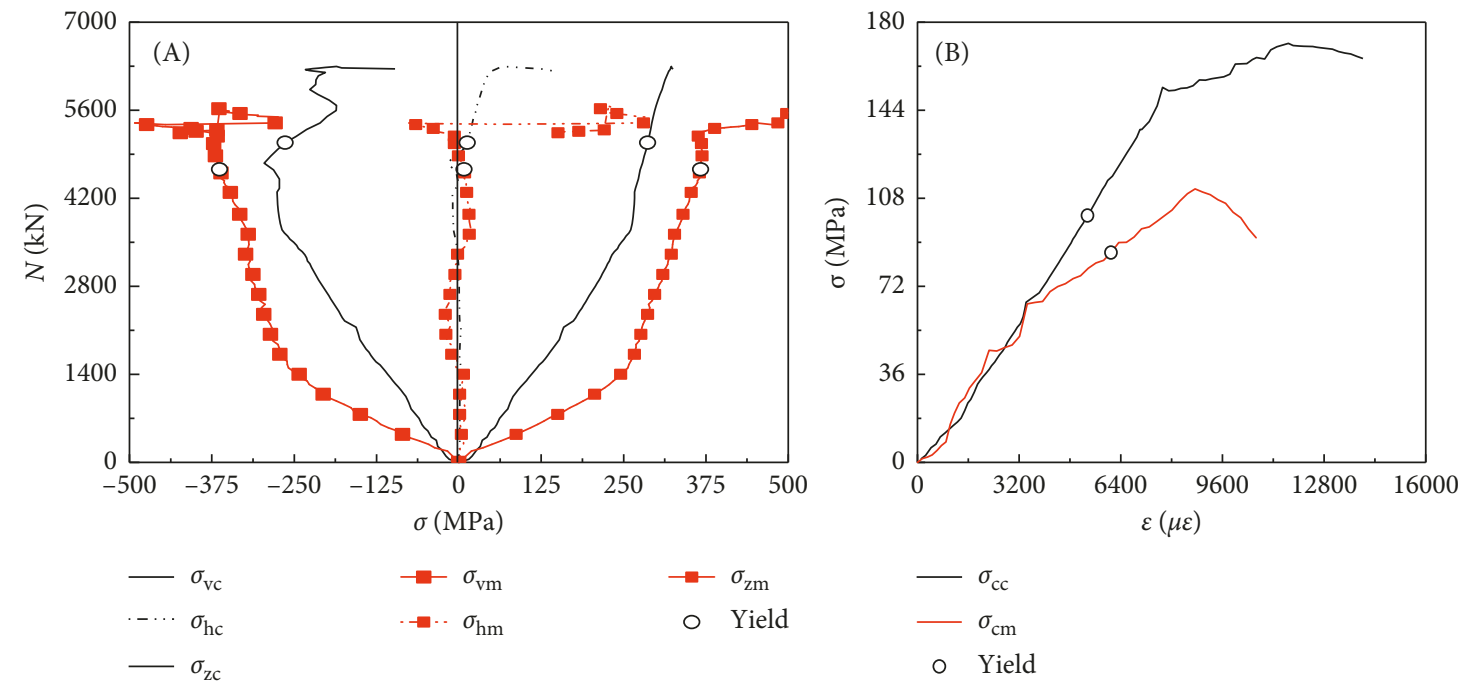

(a)
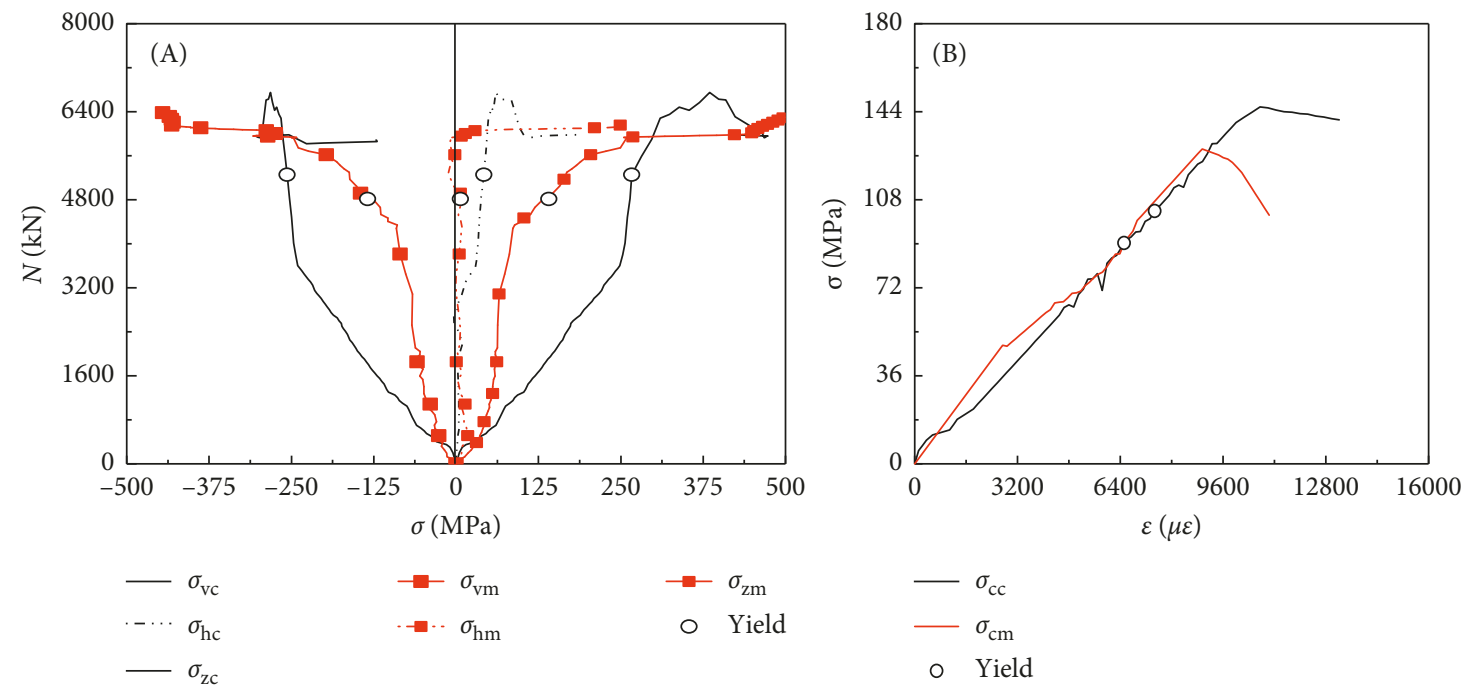

$$
\begin{aligned}
& -\sigma_{\mathrm{cc}} \\
& -\sigma_{\mathrm{cm}} \\
& \circ \quad \text { Yield }
\end{aligned}
$$

(b)
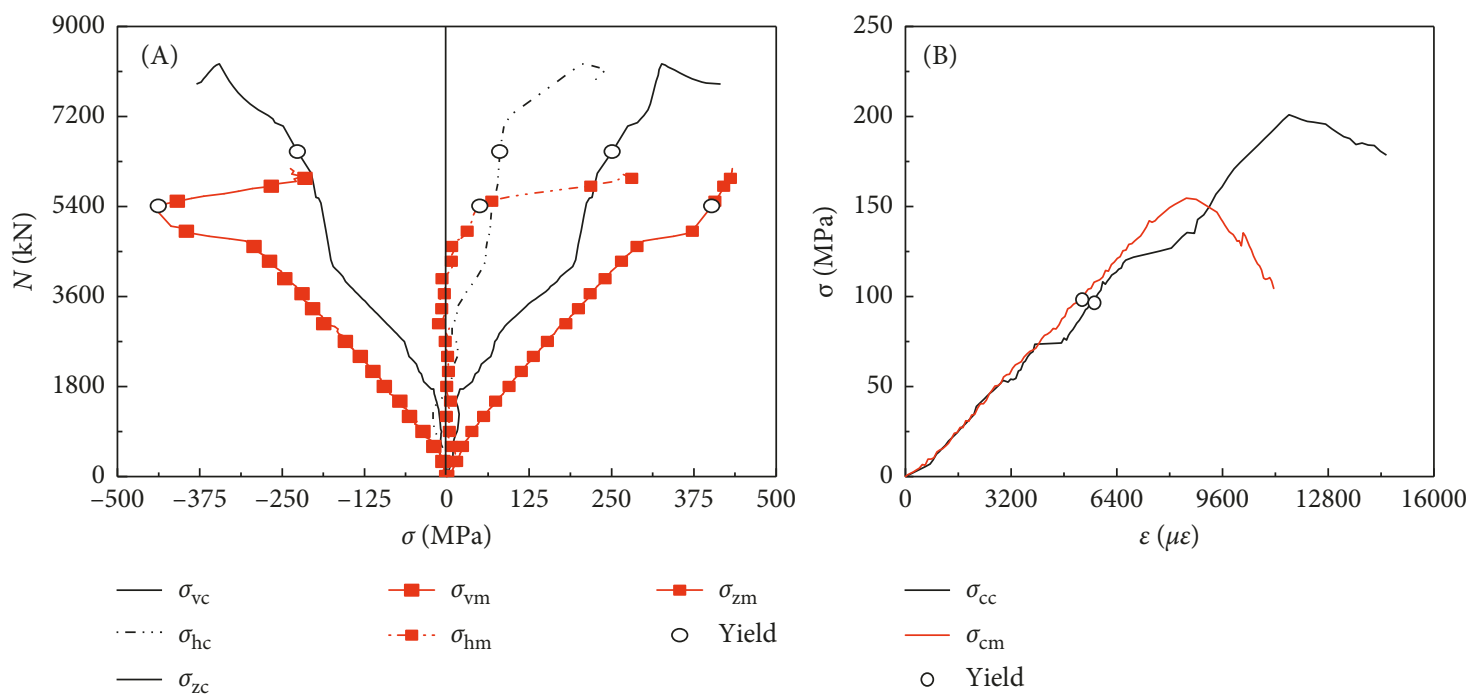

$$
\begin{aligned}
& -\ldots \sigma_{\mathrm{vc}} \\
& \rightarrow-\sigma_{\mathrm{vm}} \\
& \sigma_{\mathrm{zm}} \\
& -\sigma_{\mathrm{cc}} \\
& -\sigma_{\mathrm{cm}}
\end{aligned}
$$

(c)

Figure 9: Continued. 

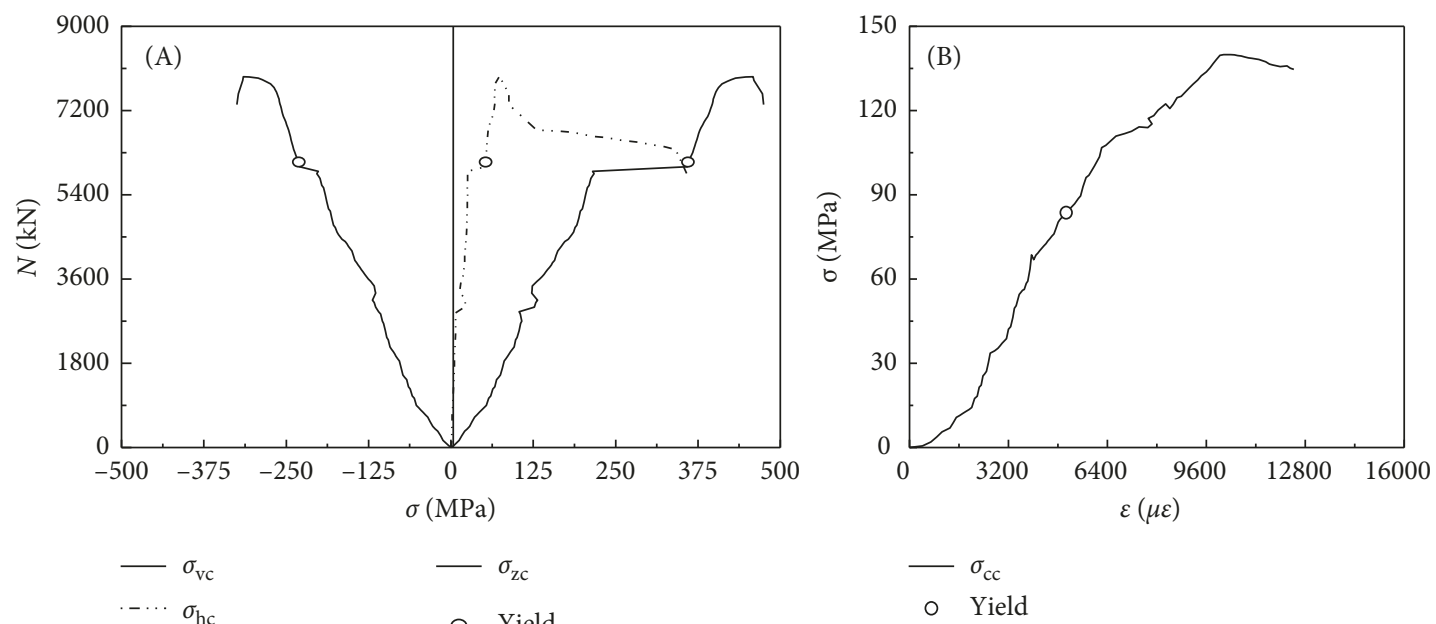

(d)
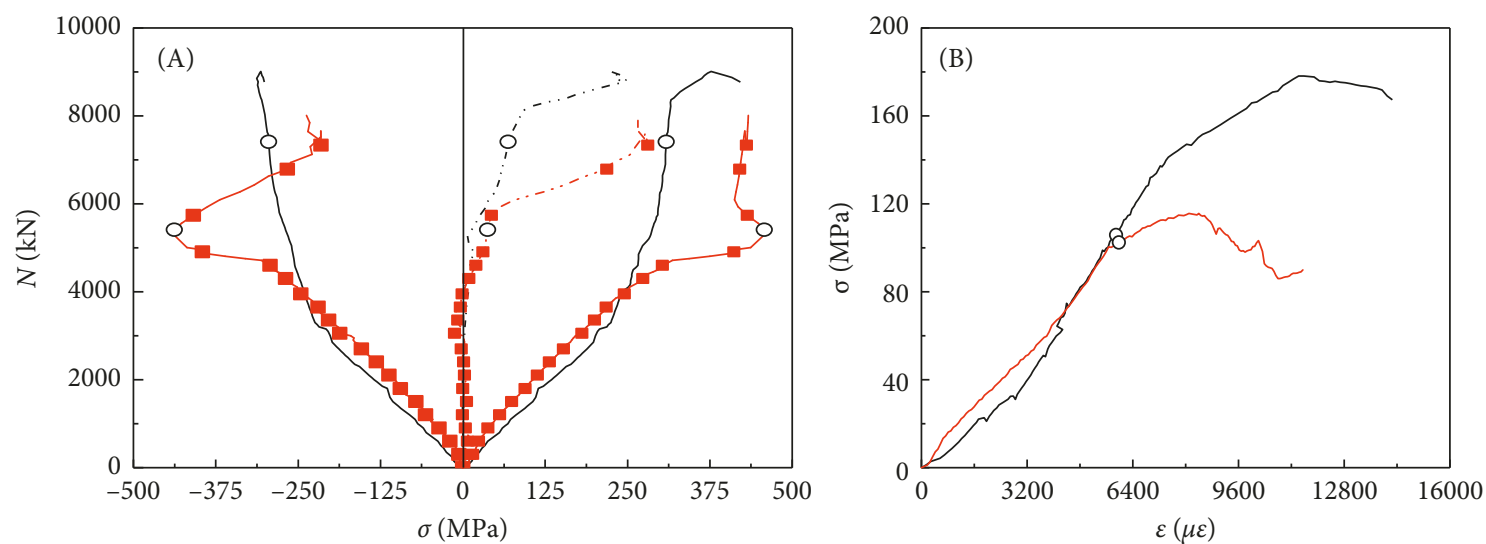

$-\sigma_{\mathrm{vc}}$
$-\cdots \sigma_{\mathrm{hc}}$
$-\sigma_{\mathrm{zc}}$

$\rightarrow \sigma_{\mathrm{zm}}$

$\rightarrow-\sigma_{\mathrm{vm}}$

○ Yield

$-\sigma_{\mathrm{cc}}$

$-\sigma_{\mathrm{cm}}$

○ Yield

(e)
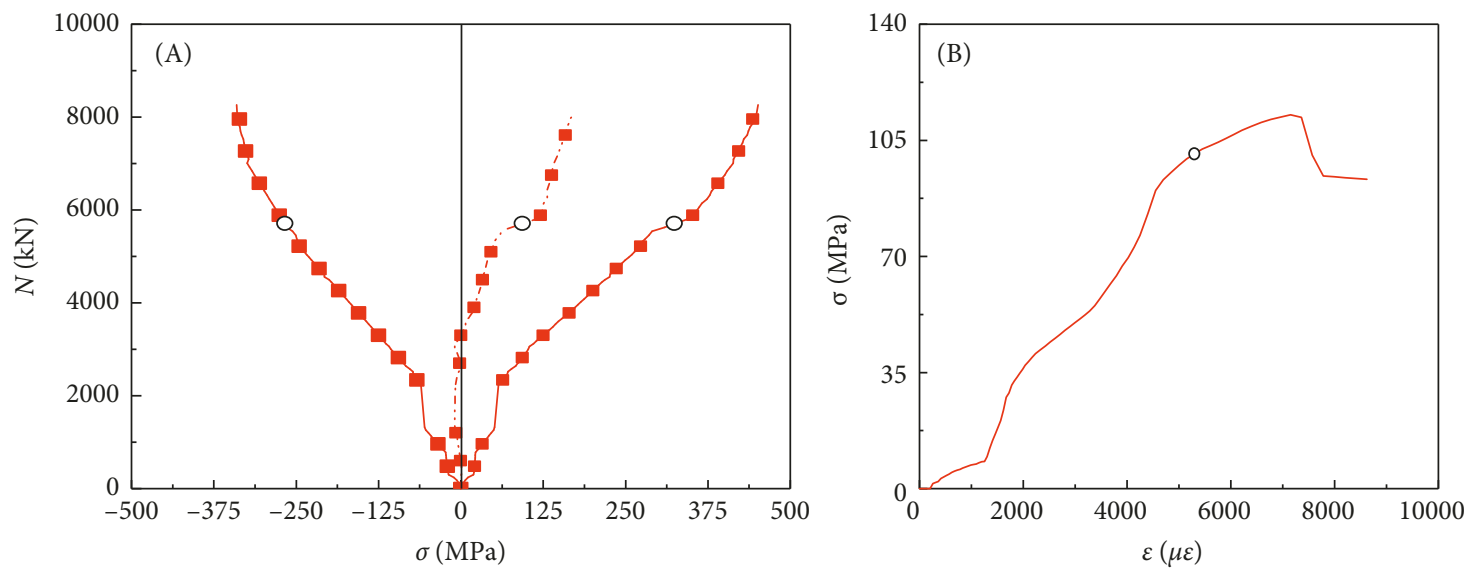

$\begin{array}{ll}-\sigma_{\mathrm{vm}} & -\sigma_{\mathrm{zm}} \\ -\sigma_{\mathrm{hm}} & \circ \text { Yield }\end{array}$

$-\sigma_{\mathrm{cm}}$

○ Yield

(f)

Figure 9: Continued. 

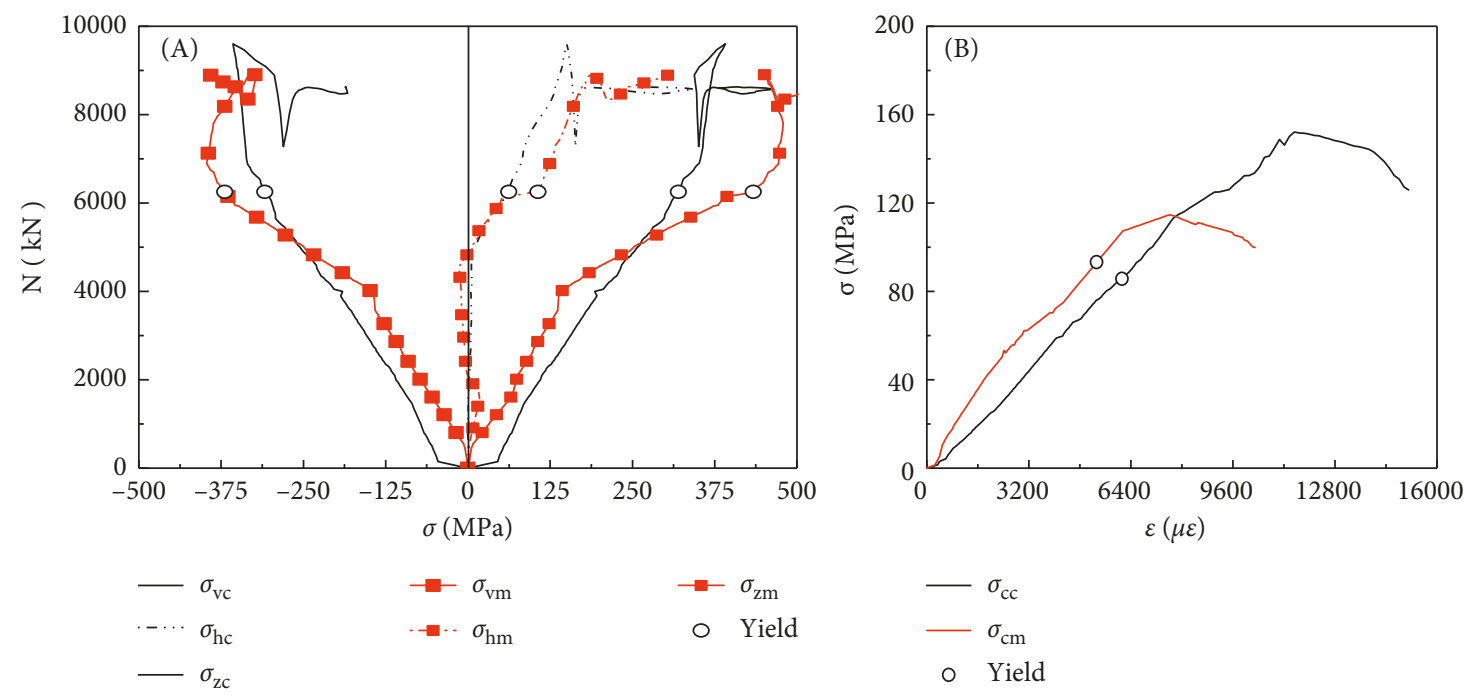

(g)

FiguRE 9: Stress-strain analysis results of RFCT specimens. (A) Envelope curves of load-steel stress and (B) stress-strain curves of RPC core for (a) 219-8, (b) 219-10, (c) 219-12, (d) 245-8, (e) 245-12, (f) 273-8, and (g) 273-10.

the tube was stressed more in the transverse direction than in the axial direction, and the steel tube began to buckle locally.

Given the same diameter of columns, the confinement coefficient increases with the decrease of diameter-thickness ratio, and the hoop stresses are increased. The peak stress and the strain at peak stress of RPC increased when surrounded by the steel tube. There was a slightly descending segment for core RPC after the axial compressive strength exceeded the peak stress. It is concluded that if RPC is confined by a steel tube, both the ultimate bearing capacity and the ductility will be improved even though different loading types showed varying degrees of improvement. The plastic stress is converted from the measured strains; the equation of measured strains and plastic stress was derived from Reference [37]. As shown in Figure 9, compressive strength, as well as the ultimate strain, of confined RPC under cyclic axial load was similar as that under monotonic axial load.

4.3. Compressive Strength of Confined RPC. Previous researchers [38] proposed a reasonable stress-strain model to analyze confined concrete. This paper used Mander's model [38] to predict the compressive strength of confined RPC of the RFCT columns as

$$
f_{\mathrm{cc}}=f_{\mathrm{c}}\left(-1.254+2.254 \sqrt{1+\frac{7.94 f_{\mathrm{r}}}{f_{\mathrm{c}}}}-2 \frac{f_{\mathrm{r}}}{f_{\mathrm{c}}}\right),
$$

where $f_{\mathrm{r}}$ is the confinement stress provided by the steel tube to the RPC and can be calculated by the following equation:

$$
f_{\mathrm{r}}=\frac{2 t \sigma_{\mathrm{h}}}{D-2 t}
$$

where $\sigma_{\mathrm{h}}$ is the hoop stress of the steel tube and should be calculated based on the longitudinal stress $\sigma_{\mathrm{v}}$ and the von Mises yield criteria. Figure 10 compares the compressive strength of confined RPC obtained from the experiment $\left(f_{\mathrm{cc}, \mathrm{e}}\right)$ and equation (5) $\left(f_{\mathrm{cc}, \mathrm{c}}\right)$. The results indicate that compressive strength of confined RPC can be predicted by Mander's model.

\section{Axial Compressive Strength of RFCT Columns}

Compressive strength of RFCT columns in this experimental study was compared with the design strength as proposed by Eurocode 4(2012) [39]. The EC4 equations for compressive strength of concrete-filled steel tube are as follows, in which equation (7) neglects the confining effect, while equation (8) considers the confining effect with the relative slenderness $\bar{\lambda} \leq 0.5$ :

$$
\begin{aligned}
& N_{\mathrm{u} 1}=A_{\mathrm{c}} f_{\mathrm{c}}+A_{\mathrm{s}} f_{\mathrm{y}}, \\
& N_{\mathrm{u} 2}=\eta_{\mathrm{a}} A_{\mathrm{s}} f_{\mathrm{y}}+A_{\mathrm{c}} f_{\mathrm{c}}\left(1+\eta_{\mathrm{c}} \frac{t}{D} \frac{f_{\mathrm{y}}}{f_{\mathrm{ck}}}\right),
\end{aligned}
$$

where $A_{\mathrm{s}}$ and $A_{\mathrm{c}}$ are the cross-sectional areas of the steel tube and RPC and $t$ and $D$ are the thickness and diameter of the steel tube.

$\eta_{\mathrm{a}}$ and $\eta_{\mathrm{c}}$ are given by the following expressions:

$$
\begin{aligned}
& \eta_{\mathrm{a}}=0.25(3+2 \bar{\lambda}), \\
& \eta_{\mathrm{c}}=4.9-18.5 \bar{\lambda}+17 \bar{\lambda}^{2},
\end{aligned}
$$

where $\bar{\lambda}$ is the relative slenderness and is calculated as

$$
\bar{\lambda}=\sqrt{\frac{N_{\mathrm{ul}}}{N_{\mathrm{cr}}}} .
$$

$N_{\mathrm{cr}}$ is the elastic critical normal force and is calculated as 


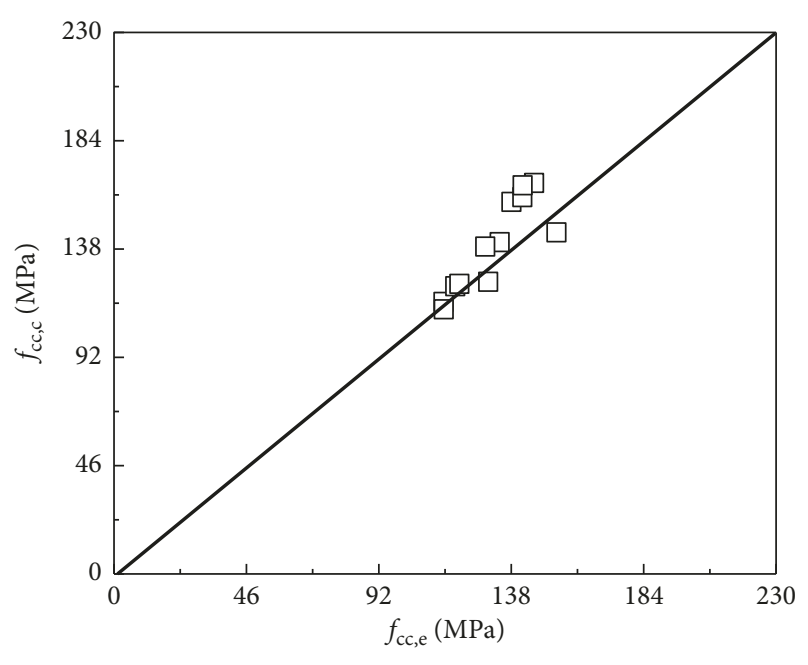

This study

Figure 10: Comparison between test results and Mander's model.

$$
N_{\mathrm{cr}}=\frac{\pi^{2}(E I)_{\mathrm{eff}}}{L^{2}}
$$

where

$$
(E I)_{\mathrm{eff}}=E_{\mathrm{s}} I_{\mathrm{s}}+0.6 E_{\mathrm{c}} I_{\mathrm{c}},
$$

where $E_{\mathrm{s}}$ and $E_{\mathrm{c}}$ are the elastic moduli of steel and RPC and $I_{\mathrm{s}}$ and $I_{\mathrm{c}}$ are the second moments of area of the steel and RPC sections.

The results were compared in Table 1, which indicates that equation (7) is conservative to estimate compressive strength of RFCT columns in group-c and group-m. Equation (8) shows good agreement with RFCT columns under monotonic and cyclic loading. Furthermore, two different loading types (cyclic and monotonic) showed similar rules. The specimen with the minimum diameterthickness ratio $(D / t=18.3)$ exhibited the maximum value of $N_{\mathrm{ue}} / N_{\mathrm{u}}$ ratio $\left(N_{\mathrm{ue}} / N_{\mathrm{u} 1}, N_{\mathrm{ue}} / N_{\mathrm{u} 2}\right)$. For a given diameter of RFCT columns, the value of $N_{\mathrm{ue}} / N_{\mathrm{u}}$ ratio increased with a decrease in diameter-thickness ratio, except for specimens with $D=273 \mathrm{~mm}$. When the diameter-thickness ratio is less than 25 , it is effective to increase the compressive strength of RFCT columns by reducing the diameter-thickness ratio.

The comparisons between axial compressive strength calculated by equations (7) and (8) and the 167 test results $[17-19,40-45]$ as well as 13 test results in Table 1 are shown in Figures 11(a) and 11(b), respectively. The average of $N_{\mathrm{ue}} / N_{\mathrm{u} 1}$ is 1.19 and standard deviation is 0.116 , while the average of $N_{\text {ue }} /$ $N_{\mathrm{u} 2}$ is 1.07 and standard deviation is 0.090 . Results show that equation (7) can provide conservative calculation by $20 \%$ because the confinement effect is not considered. While equation (8) considering the confinement effect shows better agreement with test results, it is recommended that equation (8) can be applied to predict the compressive strength of RFCT columns.

\section{Conclusions}

This paper presented an experimental research of RFCT columns under monotonic and cyclic axial compressive loading.

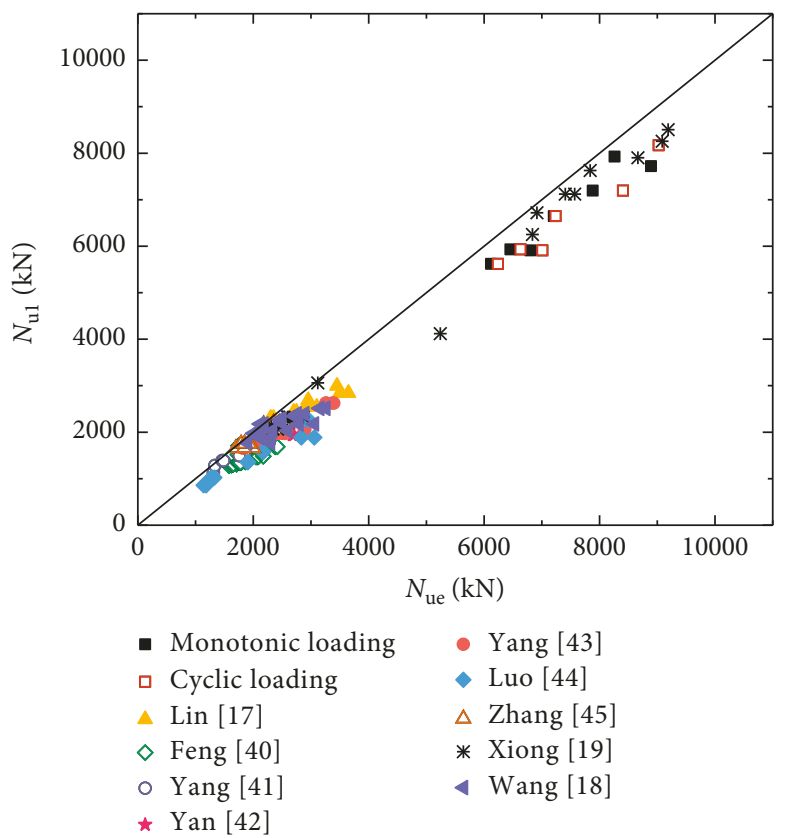

(a)

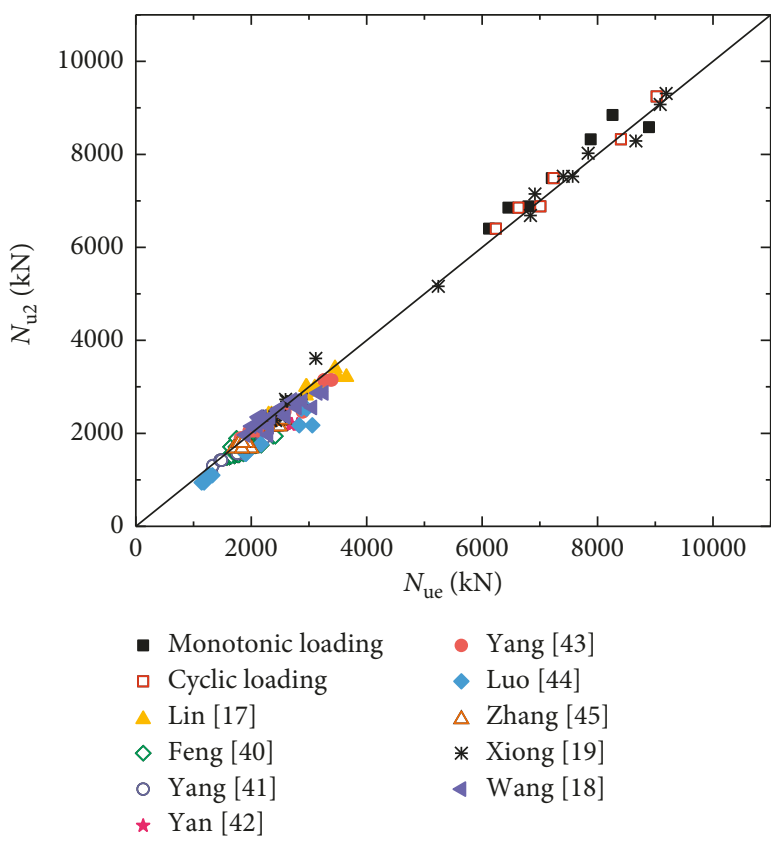

(b)

FIGURE 11: Comparison of test results with design strength based on Eurocode 4. (a) Comparison of test results with prediction from equation (7). (b) Comparison of test results with prediction from equation (8).

An equation was proposed to predict the ultimate axial compressive strength of RFCT columns. The following are the main conclusions drawn from this experimental investigation:

(1) Load-strain curves of specimens under cyclic loading were similar to the load-deformation curves of the specimens under monotonic load.

(2) Confinement coefficient had a significant influence on the failure modes and strength of RFCT stub columns. 
The specimens under cyclic loading failed in shear when the confinement coefficient was in the range of 0.53 to 0.98. With an increase in confinement coefficient, the failure mode transformed from shear failure to compressive failure for specimens under monotonic load.

(3) There was a relatively small hoop stress in the steel tube before yielding. After attaining the peak load, RPC core in RFCT columns showed a slightly descending segment in the stress-strain curve. Mander's model could predict the axial compressive strength of confined RPC.

(4) If the confinement effect is not considered, the EC4 method can provide conservative calculation by $20 \%$. It is recommended that equation (9) given by EC4 considering confinement effect can be applied to predict the compressive strength of RFCT columns.

\section{Notations}

$A_{\mathrm{s}}: \quad$ Cross-sectional area of steel tube

$A_{\mathrm{c}}$ : $\quad$ Cross-sectional area of RPC

$D: \quad$ Diameter of the steel tube

Ec: $\quad$ Elastic modulus of RPC

Es: $\quad$ Elastic modulus of steel

$f_{\mathrm{c}}$ : $\quad$ Prism compressive strength of RPC

$f_{\text {cc }}$ : Compressive strength of confined RPC

$f_{\mathrm{cc}, \mathrm{e}}, \quad$ Measured and calculated compressive strength of

$f_{\mathrm{cc}, \mathrm{c}}: \quad$ confined $\mathrm{RPC}$, respectively

$f_{\text {cu: }}$ : $\quad 70.7 \mathrm{~mm}$ cubic compressive strength of RPC

$f_{\mathrm{r}}$ : Hoop restraint stress of the steel tube

$f_{y}$ : $\quad$ Yield strength of the steel tube

L: $\quad$ Length of the RFCT column

$N$ : $\quad$ Axial load

$N_{\text {cr }}$ : Elastic critical normal force

$N_{\mu}$ : Peak load

$N_{\mathrm{u}}$ : $\quad$ Design compressive strength of RFCT column

$N_{\text {ue }}$ : Tested axial strength of RFCT column

$N_{\mathrm{y}}$ : $\quad$ Yield load of RFCT column

$R_{\mathrm{L}}$ : $\quad$ Rate of load control

$R_{\mathrm{d}}$ : $\quad$ Rate of displacement control

$t$ : Thickness of the tube

$\phi$ : Internal friction angle of concrete

$\xi: \quad$ Confinement coefficient

$\Delta: \quad$ Axial deformation of the RFCT column

$\Delta_{\mathrm{y}}: \quad$ Yield displacement

$\beta$ : $\quad$ Share angle of core RPC

$\varepsilon_{\mu}$ : $\quad$ Strain at peak load point

$\varepsilon_{\mathrm{h}}$ : Hoop strain of RFCT column

$\varepsilon_{\mathrm{v}}$ : Longitudinal strain of RFCT column

$\sigma_{\mathrm{h}}: \quad$ Hoop stress of the steel

$\sigma_{\mathrm{v}}: \quad$ Longitudinal stress of the steel

$\sigma_{\mathrm{z}}$ : $\quad$ Equivalent stress of steel tube

$\alpha$ : Strength incremental coefficient

$\bar{\lambda}$ : $\quad$ Relative slenderness.

\section{Data Availability}

The data used to support the findings of this study are available from the corresponding author upon request.

\section{Conflicts of Interest}

The authors declare that they have no conflicts of interest.

\section{Acknowledgments}

The study presented in this paper was supported by the National Natural Science Foundation of China (nos. 51408167 and 51578184), the Foundation of Key Lab of Structural Dynamics Behavior and Control of the Ministry of Education (HITCE201605), the Harbin Institute of Technology, the Natural Scientific Foundation of Heilongjiang Province (QC2017058), the Fundamental Research Funds of Harbin University of Science and Technology (LGYC2018JQ018), and the University Nursing Program for Young Scholars with Creative Talents in Heilongjiang Province (UNPYSCT-2017085).

\section{References}

[1] M. Cheyrezy, V. Maret, and L. Frouin, "Microstructural analysis of RPC (reactive powder concrete)," Cement and Concrete Research, vol. 25, no. 7, pp. 1491-1500, 1995.

[2] A. Feylessoufi, F. Villieras, and P. Richard, "Water environment and nonstructural network in a reactive powder concrete," Cement and Concrete Composites, vol. 18, no. 7, pp. 23-29, 1996.

[3] C. Mehmet, "The effect of high temperature on reactive powder concrete," Construction and Building Materials, vol. 70, pp. 508-513, 2012.

[4] X. Hou, S. Cao, Q. Rong, W. Zheng, and G. Li, "Effects of steel fiber and strain rate on the dynamic compressive stress-strain relationship in reactive powder concrete," Construction and Building Materials, vol. 170, pp. 570-581, 2018.

[5] M. Behloul and K. C. Lee, "Ductalr Seonyu footbridge," Structural Concrete, vol. 4, no. 4, pp. 195-201, 2003.

[6] P. Y. Blais and M. Couture, "Precast, prestressed pedestrian bridge world's first reactive powder concrete structure," $P C I$ Journal, vol. 44, no. 5, pp. 60-71, 1999.

[7] G.-F. Peng, X.-J. Niu, Y.-J. Shang, D.-P. Zhang, X.-W. Chen, and H. Ding, "Combined curing as a novel approach to improve resistance of ultra-high performance concrete to explosive spalling under high temperature and its mechanical properties," Cement and Concrete Research, vol. 109, pp. 147-158, 2018.

[8] M. Abid, X. Hou, W. Zheng, and R. R. Hussain, "High temperature and residual properties of reactive powder concrete-a review," Construction and Building Materials, vol. 147, pp. 339-351, 2017.

[9] X. Hou, P. Ren, Q. Rong, W. Zheng, and Y. Zhan, "Effect of fire insulation on fire resistance of hybrid-fiber reinforced reactive powder concrete beams," Composite Structures, vol. 209, pp. 219-232, 2019.

[10] W. Z. Zheng, X. M. Hou, D. S. Shi, and M. X. Xu, "Experimental study on concrete spalling in prestressed slabs subjected to fire," Fire Safety Journal, vol. 45, no. 5, pp. 283-297, 2010.

[11] G. Li, B. Chen, Z. Yang, and Y. Feng, "Experimental and numerical behaviour of eccentrically loaded high strength concrete filled high strength square steel tube stub columns," Thin-Walled Structures, vol. 127, pp. 483-499, 2018. 
[12] J. Y. R. Liew, M. Xiong, and D. Xiong, "Design of concrete filled tubular beam-columns with high strength steel and concrete," Structures, vol. 8, no. 2, pp. 213-226, 2016.

[13] L. Guo, Y. Liu, H. Jiao, and S. An, "Behavior of thin-walled circular hollow section stub columns under axial compression," International Journal of Steel Structures, vol. 16, no. 3, pp. 777-787, 2016.

[14] P. Sun, F. K. Cui, H. Y. Qin, and X. M. Hou, "Study on regular inspection frequency of bridge based on seismic vulnerability analysis," Shock and Vibration, vol. 2018, Article ID 7157038, 11 pages, 2018.

[15] J. P. Liu, S. M. Zhang, X. D. Zhang, and L. H. Guo, "Behavior and strength of circular tube confined reinforced-concrete (CTRC) columns," Journal of Constructional of Steel Research, vol. 64, pp. 1473-1482, 2008.

[16] H. Qi, L. Guo, J. Liu, D. Gan, and S. Zhang, "Axial load behavior and strength of tubed steel reinforced-concrete (SRC) stub columns," Thin-Walled Structures, vol. 49, no. 9, pp. 1141-1150, 2011.

[17] Z. Y. Lin, Y. H. Wu, and Z. Y. Shen, "Research on behavior of RPC filled circular steel tube column subjected to axial compressive," Journal of Building Structures, vol. 26, no. 4, pp. 52-57, 2005, in Chinese.

[18] S. H. Liu, L. H. Li, and L. Wang, "Study on behavior of RPC filled steel tubular stub columns under axial compression," Strength of Materials, vol. 49, no. 1, pp. 133-138, 2017.

[19] M.-X. Xiong, D.-X. Xiong, and J. Y. R. Liew, "Axial performance of short concrete filled steel tubes with high- and ultrahigh- strength materials," Engineering Structures, vol. 136, pp. 494-510, 2017.

[20] M.-X. Xiong, D.-X. Xiong, and J. Y. R. Liew, "Flexural performance of concrete filled tubes with high tensile steel and ultra-high strength concrete," Journal of Constructional Steel Research, vol. 132, pp. 191-202, 2017.

[21] M.-X. Xiong, D.-X. Xiong, and J. Y. R. Liew, "Behaviour of steel tubular members infilled with ultra high strength concrete," Journal of Constructional Steel Research, vol. 138, pp. 168-183, 2017.

[22] Y. Shi, M. Wang, and Y. Wang, "Experimental and constitutive model study of structural steel under cyclic loading," Journal of Constructional Steel Research, vol. 67, no. 8, pp. 1185-1197, 2011.

[23] J. Liu, Y. Teng, Y. Zhang, X. Wang, and Y. F. Chen, "Axial stress-strain behavior of high-strength concrete confined by circular thin-walled steel tubes," Construction and Building Materials, vol. 177, pp. 366-377, 2018.

[24] J. Liu and X. Zhou, "Behavior and strength of tubed RC stub columns under axial compression," Journal of Constructional Steel Research, vol. 66, no. 1, pp. 28-36, 2010.

[25] J. Fitzwilliam and L. A. Bisby, "Slenderness effects on circular CFRP confined reinforced concrete columns," Journal of Composites for Construction, vol. 14, no. 3, pp. 280-288, 2010.

[26] Q. Wang, Q. Shi, E. M. Lui, and Z. Xu, "Axial compressive behavior of reactive powder concrete-filled circular steel tube stub columns," Journal of Constructional Steel Research, vol. 153, pp. 42-54, 2019.

[27] X. Y. Lv, Y. Wang, C. J. Fu, and W. Z. Zheng, "Basic mechanical property indexes of reactive powder concrete," Journal of Harbin Institute of Technology, vol. 46, no. 10, pp. 1-9, 2014, in Chinese.

[28] Y. Y. Wang and S. M. Zhang, "Shear resistant behavior of axially loaded high-strength concrete-filled steel tubular stub columns," Journal of Building Structures, vol. 30, no. 2, pp. 114-124, 2009, in Chinese.
[29] P. Stemberk and A. Kohoutkova, "Image-analysis-based measuring of lateral deformation of hardening concrete," Material Science, vol. 11, no. 3, pp. 292-296, 2005.

[30] K. Z. Ke and R. Z. Zhou, "Compressive mechanics of carbon fiber RPC," Journal of Fuzhou University (Natural Science), vol. 34, no. 5, pp. 739-744, 2006, in Chinese.

[31] M. Abid, X. Hou, W. Zheng, and R. Hussain, "Effect of fibers on high-temperature mechanical behavior and microstructure of reactive powder concrete," Materials, vol. 12, no. 2, p. 329, 2019.

[32] Y. Tian, Experimental Research on Size Effect of ConcreteFilled Steel Tubular Stub Columns under Axial Compressive Load, Master Thesis, Harbin Institute of Technology, China, 2014, in Chinese.

[33] Y. Teng, Research on Constitutive Relation of Circular Tube Confined High Strength Concrete, Master Thesis, Chongqing University, China, 2016, in Chinese.

[34] Z. Y. Wang and J. Li, "Uniaxial compressive behavior of reactive powder concrete adding nano- silicon dioxide," Concrete, vol. 10, pp. 88-95, 2009.

[35] Y. H. Wu, Z. Y. Lin, and S. P. Sun, "Experimental research on mechanical properties of RPC," Journal of Shandong University of Architecture and Engineering, vol. 19, no. 3, pp. 7-11, 2004, in Chinese.

[36] J. X. Zeng, Y. H. Wu, and Q. Lin, "Research on the compressive mechanics properties of steel fiber RPC," Journal of Fuzhou University (Natural Science), vol. 33, no. S1, pp. 132-137, 2005, in Chinese.

[37] S. M. Zhang, L. H. Guo, Z. L. Ye, and Y. Y. Wang, "Behavior of steel tube and confined high strength concrete for concretefilled RHS tubes," Advances in Structural Engineering, vol. 8, no. 5, pp. 101-116, 2005.

[38] J. B. Mander, M. J. N. Priestley, and R. Park, "Theoretical stress-strain model for confined concrete," Journal of Structural Engineering, vol. 114, no. 8, pp. 1804-1826, 1988.

[39] Eurocode 4: EN 1994-1-1, Design of Composite Steel and Concrete Structures: General Rules and Rules for Buildings, 2012.

[40] J. W. Feng, "Study on Mechanical behavior of reactive powder concrete filled steel tubular columns," Master Thesis, Tsinghua University,2008, in Chinese.

[41] W. S. Yang, "Research on mechanical properties and ultimate loading capacity of reactive powder concrete filled steel tubes columns," Master Thesis, Hunan University, 2003, in Chinese.

[42] Z. G. Yan, W. Q. Zhang, and M. Z. An, "Analysis of ultimate loading capacity for circular RPC filled steel tube stub columns under axial compression," Journal of Beijing university of technology, vol. 37, no. 3, pp. 361-367, 2011, in Chinese.

[43] G. J. Yang, "Research on behavior and ultimate bearing capacity of RPC-filled steel tube columns under axial compression," Master Thesis, Beijing Jiaotong University, 2013, in Chinese.

[44] H. Luo, W. Y. Ji, Z. G. Yan, and W. W. Li, "Research on influence of loading methods on compressive behavior of reactive power concrete filled tube stub columns under axial loads," Journal of the China Railway Society, vol. 36, no. 9, pp. 105-110, 2014, in Chinese.

[45] J. Zhang, "Research on the compressive behavior of RPC-filled steel tube columns," Master Thesis, Fuzhou University, 2003, in Chinese. 


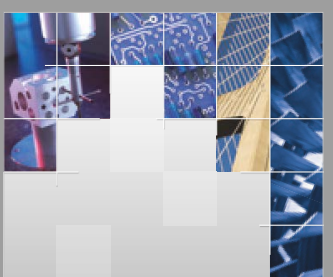

\section{Enfincering}
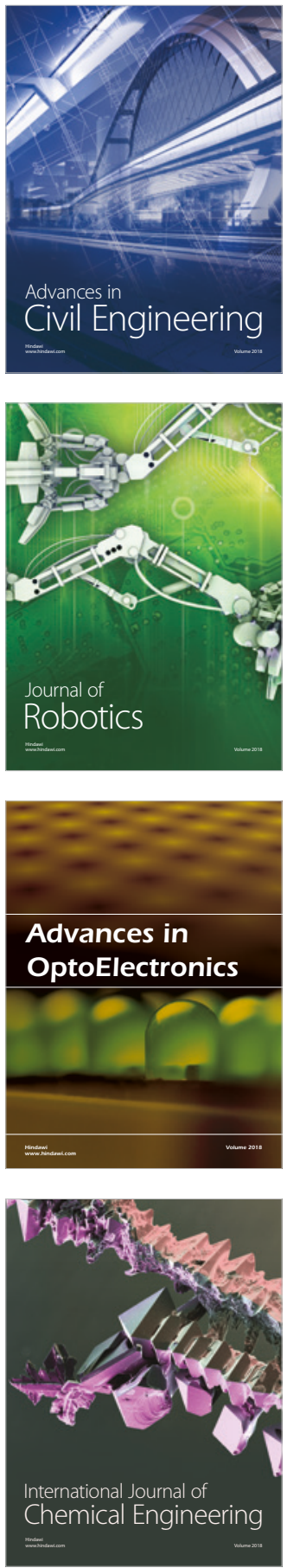

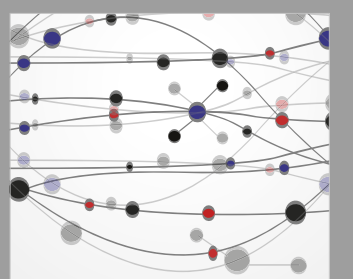

\section{Rotating \\ Machinery}

The Scientific World Journal

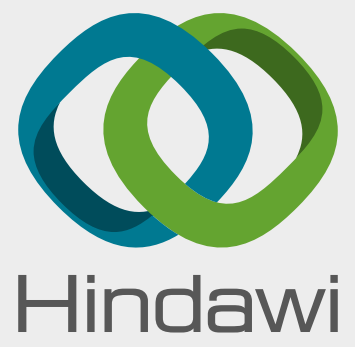

Submit your manuscripts at

www.hindawi.com
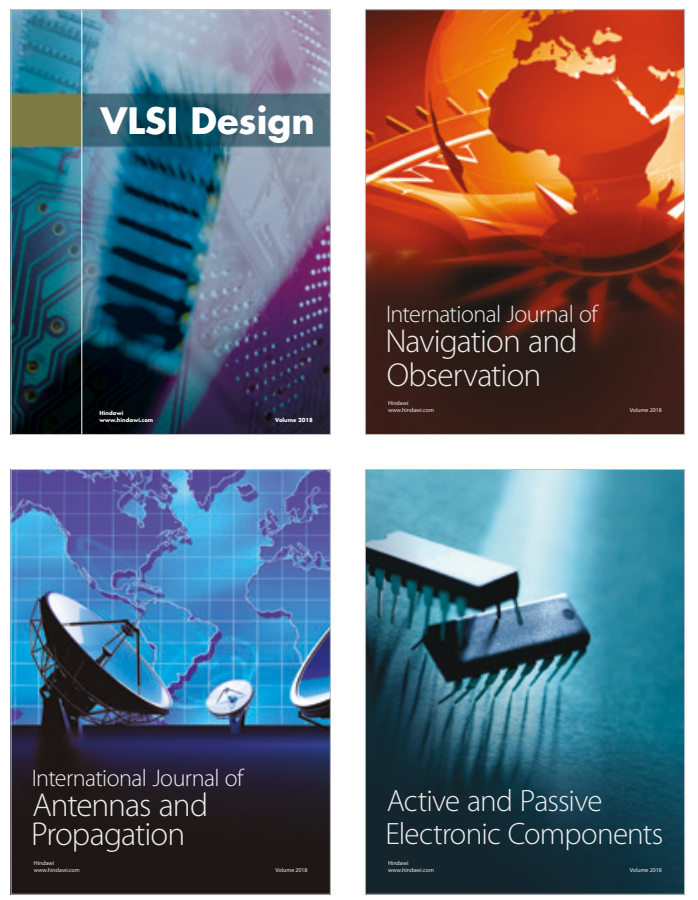
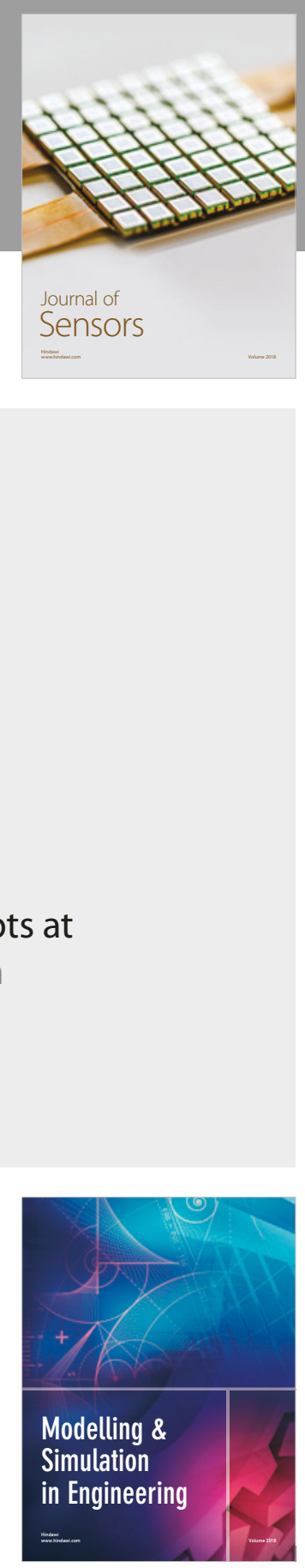

\section{Advances \\ Multimedia}
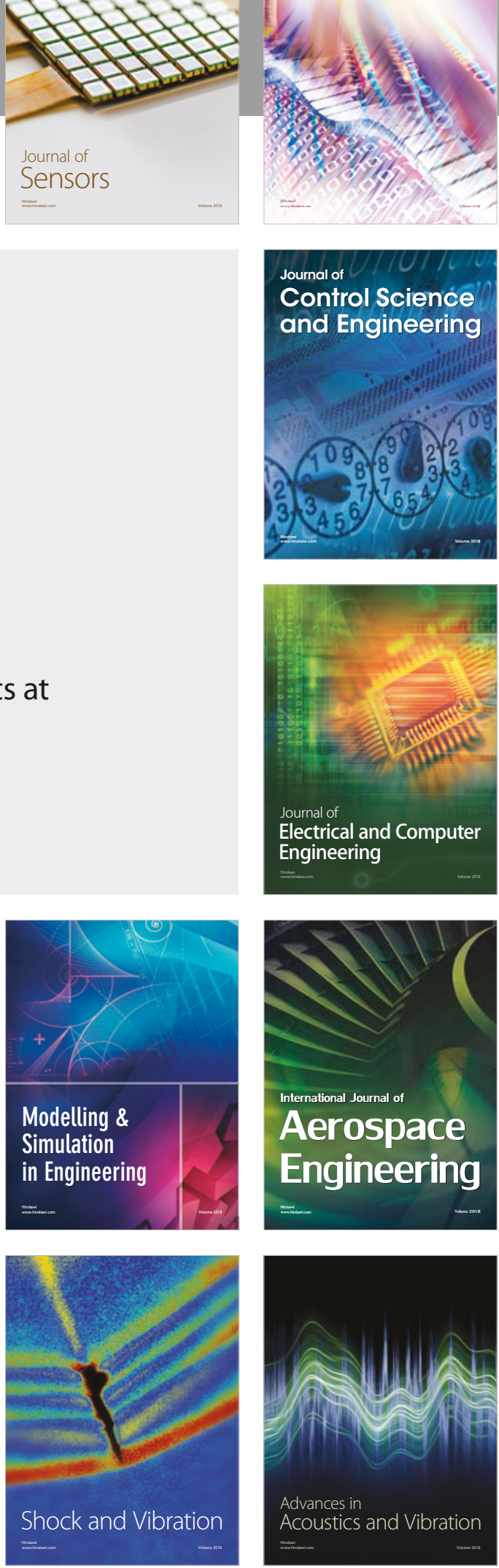